\title{
Targeted CRISPR-Cas9-based gene knockouts in the model brown alga Ectocarpus
}

Yacine Badis ${ }^{1,2}$ Orcid: 0000-0003-1606-3906, Delphine Scornet ${ }^{1}$ Orcid: 00000001-5332-199X, Minori Harada ${ }^{3}$, Céline Caillard1, Olivier Godfroy ${ }^{1}$ Orcid: 00000002-8963-8371, Morgane Raphalen1, Claire M.M. Gachon ${ }^{2,4}$ Orcid: 0000-0002-

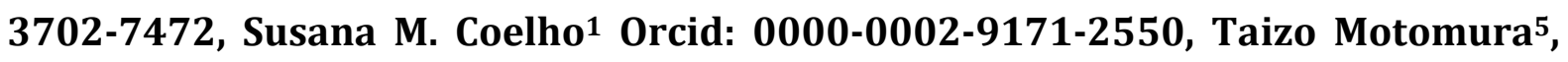
Chikako Nagasato ${ }^{5} \&$ J. Mark Cock $^{1}$ 0000-0002-2650-0383

${ }^{1}$ Roscoff Biological Station, Place Georges Teissier, 29680 Roscoff, France; ${ }^{2}$ The Scottish Association for Marine Science, Scottish Marine Institute, Oban, Argyll PA37 1QA, United Kingdom; ${ }^{3}$ Graduate School of Environmental Science, Hokkaido University, Sapporo 060-0810 Japan; ${ }^{4}$ Muséum National d'Histoire Naturelle, UMR 7245 Molécules de Communication et Adaptation des Micro-organismes, CP 54, 57 rue Cuvier, 75005 Paris, France; 5Muroran Marine Station, Field Science Center for Northern Biosphere, Hokkaido University, Muroran 051-0013, Japan.

Author for correspondence:

Yacine Badis

Tel: +33298292360

Yacine.Badis@sams.ac.uk

Accepted: 20th May 2021

Keywords:

Brown alga, CRISPR, Cas9, Ectocarpus, reverse genetics, transformation

\section{Summary}

- Brown algae are an important group of multicellular eukaryotes, phylogenetically distinct from both the animal and land plant lineages. Ectocarpus has emerged as a model organism to study diverse aspects of brown algal biology but this system 
currently lacks an effective reverse genetics methodology to analyse the functions of selected target genes.

- Here we report that mutations at specific target sites are generated following the introduction of CRISPR-Cas9 ribonucleoproteins into Ectocarpus cells, using either biolistics or microinjection as the delivery method.

- Individuals with mutations affecting the ADENINE PHOSPHORIBOSYL TRANSFERASE $(A P T)$ gene were isolated following treatment with 2-fluoroadenine and this selection system was used to isolate individuals in which mutations had been introduced simultaneously at APT and at a second gene. This double mutation approach could potentially be used to isolate mutants affecting any Ectocarpus gene, providing an effective reverse genetics tool for this model organism.

- The availability of this tool will significantly enhance the utility of Ectocarpus as a model organism for this ecologically and economically important group of marine organisms. Moreover, the methodology described here should be readily transferable to other brown algal species.

\section{Key words:}

Brown alga, CRISPR, Cas9, Ectocarpus, reverse genetics, transformation

\section{Introduction}

Brown seaweeds (i.e. algae of the class Phaeophyceae) are currently attracting considerable interest for both fundamental and applied research. Features of fundamental interest include their complex life cycles and the fact that they have evolved complex multicellular development independently of other major lineages such as animals and land plants (Coelho \& Cock, 2020). From an applied point of view, their evolutionary history as part of the stramenopile group has also been important, resulting in the emergence of a diverse range of unique algal metabolites (McHugh, 2003). Brown algae also play important ecological roles (Klinger, 2015). They are often the predominant primary producers in rocky shore ecosystems, providing habitats for other species and making an important contribution to global carbon sequestration (Ortega et al., 2019). Given their key ecological role, it is also important to understand brown algal biology in order to address current environmental challenges resulting from the unprecedented pace of global warming. Seaweeds have the capacity to significantly mitigate climate change through carbon sequestration (Chung et al., 2011; Duarte et al., 2017) but, at the same time, changes to 
the coastal environments threaten the resilience of natural seaweed populations (Wahl et al., 2015; Coleman \& Wernberg, 2017; Coleman \& Goold, 2019).

Within the brown algae, members of the Ectocarpales have several features, such as short life cycles, small size at maturity and small genome sizes, that make them well adapted for genetic studies. One member of this order, the filamentous brown alga Ectocarpus siliculosus (currently referred to as Ectocarpus species 7, see the Methods section for further details), was proposed as a model species in 2004 (Peters et al., 2004). A broad range of tools and resources were subsequently established for this organism including the complete sequence of its genome (the first to be sequenced for a macroalga; Cock et al., 2010; Cormier et al., 2017), stramenopileadapted bioinformatics tools (Gschloessl et al., 2008), microarrays and RNA-seq-based transcriptomic data, the latter for both protein-coding and non-coding genes (Dittami et al., 2009; Ritter et al., 2014; Tarver et al., 2015; Lipinska et al., 2015; Strittmatter et al., 2016; Cormier et al., 2017), proteomic (Ritter et al., 2010) and epigenetic methodologies (Bourdareau et al., 2021). In addition, genetic tools have been established, including sequence-tagged genetic maps (Heesch et al., 2010; Avia et al., 2017), mutant collections and forward genetic screens (Macaisne et al., 2017; Godfroy et al., 2017; Arun et al., 2019). These resources have been used to investigate diverse aspects of brown algal biology and Ectocarpus species 7 is currently the most intensely studied species within the brown algae. Recent advances include the identification of quantitative genetic loci associated with adaptation to environmental stresses (Avia et al., 2017) and the identification of genes that act as master regulators of the life cycle (Arun et al., 2019) or that play important roles in other developmental processes (Macaisne et al., 2017; Godfroy et al., 2017).

These studies have illustrated the potential of Ectocarpus species 7 as a model system but, whilst important advances have been made, the absence of a reverse genetics tool for this organism remains an important constraint, limiting the scope of functional approaches that can be applied. Indeed, the absence of a genetic transformation system has been repeatedly highlighted as an important bottleneck for brown algal research (Kroth, 2013; Mikami, 2014). A protocol for stable plasmid-based transformation has been recently developed for the green macroalga Ulva mutabilis (Oertel et al., 2015) and there have been reports of transient expression of transgenes in red macroalgae (Hirata et al., 2011; Mikami, 2014). For brown algae, earlier studies reported transient expression (Jiang et al., 2003) and stable integration (Zhang et al., 2008) of foreign genes in the kelp Saccharina (formerly Laminaria) japonica but to date these methods have not been replicated nor widely adopted by the phycological community. An alternative approach, involving injection of double stranded RNA has been shown to induce RNA-interference-based gene silencing in Fucus serratus embryos (Farnham et al., 2013) and a 
modification of this protocol based on transfection of small interfering RNAs into gametes has been used to investigate gene function during early development of Ectocarpus species 7 partheno-sporophytes (Macaisne et al., 2017; Godfroy et al., 2017). However, RNA interference is still very inefficient in Ectocarpus species 7, affecting only a small proportion of the transfected cells, and is only applicable for genes that have phenotypes very early during development.

CRISPR-Cas9 is a bacteria-derived ribonucleoprotein (RNP) complex that uses a sequencespecific guide RNA to detect and cut sites complementary to the guide RNA in DNA. CRISPRCas9-based approaches have been used successfully to induce targeted mutations in the genomes of several unconventional model organisms, including oomycetes (Fang et al., 2017) and diatoms (Nymark et al., 2016), which, like the brown algae, are members of the stramenopile lineage. Deployment of CRISPR-Cas9 in oomycetes and diatoms used pre-existing DNA transformation protocols, an approach that is currently unavailable for brown algae. In contrast, direct delivery of CRISPR-Cas9 ribonucleoproteins (RNPs), as first demonstrated in Caenorhabditis elegans (Cho et al., 2013) does not require the existence of a transformation protocol and this approach could therefore be potentially applied to brown algal models. Direct delivery of CRISPR-Cas9 RNPs has been recently adapted for the model diatom Phaeodactylum tricornutum to target endogenous counter-selectable marker genes, resulting in a DNA-free gene knock-out system (Serif et al., 2018). The latter study notably targeted the Adenine Phosphoribosyl Transferase (APT) gene, using 2-fluoroadenine (2-FA) resistance as a screen to select single or multiple gene knock-out mutants.

In this study, we show that direct delivery of CRISPR-Cas9 RNPs can be used to induce targeted mutagenesis (TM) events in the brown alga Ectocarpus species 7. Initial experiments used a droplet digital PCR assay to detect TM events in populations of bombarded cells. Then CRISPRCas9 RNPs targeting the Ectocarpus species 7 APT gene were used to generate 2-FA resistant (2FAR) individuals bearing genetic mutations within the targeted regions of the APT locus. Two different CRISPR-Cas9 RNP introduction methods were used to generate 2-FAR individuals. Biolistic bombardment of Ectocarpus species 7 gametes produced 2-FAR partheno-sporophytes, whereas laser-assisted thermal-expansion microinjection of RNPs into developing unilocular sporangia generated 2-FAR gametophytes. Finally, we showed that simultaneous introduction of two different CRISPR-Cas9 RNPs, using either the biolistic or the microinjection approach, generated double gene knock-outs, affecting both the selectable APT marker gene and one of three different additional, non-selected target genes. This study provides the first evidence of functional gene knock-outs in a brown alga, opening a long-awaited era of reverse genetics for this key lineage. The availability of two different delivery strategies, biolistics and 
microinjection, allowing delivery of RNPs at different stages of the life cycle expands the scope of application of this new technology for the elucidation of brown algal gene function. Moreover, both of the targeted life cycle stages (partheno-sporophytes and gametophytes) are haploid, allowing direct observation of any phenotype associated with a mutated allele in first generation mutant individuals.

\section{Methods}

gRNA design and in vitro validation of RNP complexes

The CRISPOR (Concordet \& Haeussler, 2018) tool (http://crispor.tefor.net/), with the Ectocarpus species 7 strain Ec32 genome as reference, was used to select the highest scoring crRNAs for exons near the 5 ' ends of target genes. Purified crRNAs, tracrRNA and Cas9 protein (HiFi Cas9 Nuclease 3NLS) were obtained from Integrated DNA Technologies (IDT; Leuven, Belgium) and assembled into RNP complexes following the manufacturer's instructions with a Cas9:gRNA ratio of 1:1. RNP in vitro cleavage assays were performed on purified PCR amplicons containing the target sites following the New England Biolabs online protocol (https://international.neb.com/protocols/2014/05/01/in-vitro-digestion-of-dna-with-cas9nuclease-s-pyogenes-m0386). Briefly, $90 \mathrm{fmol}$ of purified PCR amplicon were added to $900 \mathrm{fmol}$ of preassembled RNP complex in NEB 3.1 buffer for a final volume of $30 \mu \mathrm{L}$. The reaction was incubated for one hour at $37^{\circ} \mathrm{C}$ and the digestion was then terminated by addition of $1 \mu \mathrm{L}$ Proteinase K (NEB) and incubation for 10 minutes at $65^{\circ} \mathrm{C}$. The DNA digestion products were analysed on a $1.5 \%$ agarose gel. Supplementary Table S1 provides the sequences of the crRNAs and oligonucleotide primer sequences used in this study.

\section{Biological Material}

This study used the male Ectocarpus species 7 strain Ec32, for which a reference genome is available (Cock et al., 2010; Cormier et al., 2017). Strain Ec32 was previously referred to as E. siliculosus (Peters et al., 2004) but a recent study (Montecinos et al., 2017) indicates that it belongs to a distinct, at present unnamed, species, which is referred to provisionally as Ectocarpus species 7. Ectocarpus species 7 strain Ec32 was cultured in sterilized natural seawater enriched with half strength Provasoli solution (Starr \& Zeikus, 1993) (half-strength PES). The culture conditions were $13^{\circ} \mathrm{C}$ with a light:dark cycle of $12 \mathrm{~h}: 12 \mathrm{~h}\left(20 \mu\right.$ mol photons $\mathrm{m}^{-2}$ $\mathrm{s}^{-1}$ ) and daylight-type fluorescent tubes (Coelho et al., 2012) in the Roscoff laboratory and $15^{\circ} \mathrm{C}$ under cool white fluorescent lamps (30-40 $\mu \mathrm{mol}$ photons $\mathrm{m}^{-2} \mathrm{~s}^{-1}, 14 \mathrm{hr}$ light : $10 \mathrm{hr}$ dark) in the Muroran laboratory. All manipulations were performed under sterile conditions in a laminar flow hood. 
To obtain gametes for biolistic delivery, $2 \mathrm{~mm}$ gametophyte germlings were transferred to individual $140 \mathrm{~mm}$ petri dishes (ten gametophytes per dish) containing $70 \mathrm{~mL}$ of culture medium. For each biolistic delivery, about a hundred fertile gametophytes bearing plurilocular gametangia were collected after four weeks in culture and induced to release gametes (Coelho et al., 2012) in $60 \mathrm{~mm}$ petri dishes containing $5 \mathrm{~mL}$ of solidified (1.5\% agar) culture medium by adding $10 \mathrm{~mL}$ of ice-cold sterile natural seawater. The gametophytes were removed after 6 hours and the released gametes left to settle overnight on the agar substrate. Subsequent steps were performed using the same culture dishes as settled gametes attach firmly to the agar substrate. One hour before the experiment, the seawater medium was removed by delicate inversion, and the agar plates were left to dry for $10 \mathrm{~min}$ under a laminar flow-hood. Microparticle RNP coating and microcarrier preparation were performed as described by Serif et al. (2018). If not otherwise stated, $3 \mathrm{mg}$ of gold nanoparticles (0.6 $\mu \mathrm{m}$ diameter, Bio-Rad) loaded with CRISPR-Cas9 RNPs, consisting of $8 \mu \mathrm{g}$ of Cas9 complexed with equimolar ratios of crRNA and tracrRNA, were used for each biolistic shot. Biolistic delivery parameters were a membrane rupture pressure of $1800 \mathrm{psi}$, a vacuum of $27 \mathrm{Hg}$ and a target distance of $6 \mathrm{~cm}$. Initial tests to verify delivery of nanoparticules to different cell types were carried out using $3 \mathrm{mg}$ of gold nanoparticles ( $0.6 \mu \mathrm{m}$ diameter, Bio-Rad) that had been pre-incubated in an $8 \mathrm{mM}$ solution of AF488-labelled $10 \mathrm{kDa}$ Dextran (Invitrogen). Bombardments were carried out using a BioRad PDS-1000/He system. After bombardment, $15 \mathrm{~mL}$ of fresh culture medium was added and the gametes allowed to recover for $48 \mathrm{~h}$ prior to the application of selection, for example by addition of $20 \mu \mathrm{mM} 2$-fluoroadenine (Sigma Aldrich). For droplet digital PCR detection of TM events, biolistic delivery was performed on 2 week old immature gametophytes (5 to 6 individuals per test) spread on the same solidified medium.

Laser-assisted thermal-expansion microinjection of CRISPR-Cas9 RNP complexes

Short branches bearing immature unilocular sporangia were dissected from sporophytes of Ectocarpus species 7 strain Ec32, placed on poly-L-lysine coated coverslips and immediately pushed gently with a cotton swab to ensure firm attachment. Two or three drops of halfstrength PES medium were then added. The microinjection apparatus has been described previously (Nagasato et al., 2015, 2017). Micromanipulators consisting of a coarse manipulator (MN-4; Narishige Co. Ltd., Tokyo, Japan) and a three-axis joystick oil hydraulic micromanipulator (MO-202; Narishige) were coupled to an Olympus IX71 inverted microscope (Olympus, Tokyo, Japan). Fine glass needles were produced by pulling glass capillaries (GDC-1; Narishige) with a microcapillary Faller MCF-100 (Nepa Gene Co., Ltd., Tokyo, Japan). For the 
experiments that targeted only $A P T$, a crRNA/tracrRNA mixture was prepared by mixing $1 \mu \mathrm{l}$ of $100 \mu \mathrm{M}$ gAPT1 crRNA, $1 \mu \mathrm{l}$ of $100 \mu \mathrm{M}$ tracrRNA and $2 \mu \mathrm{l}$ of microinjection buffer (20 mM HEPES, $150 \mathrm{mM} \mathrm{KCl}$. pH 7.0), heating to $95^{\circ} \mathrm{C}$ for $5 \mathrm{~min}$ and then cooling to room temperature. The CRISPR-Cas9 RNP microinjection solution contained all $4 \mu \mathrm{l}$ of the above crRNA/tracrRNA preparation plus $0.5 \mu \mathrm{l}$ of Cas $9(100 \mu \mathrm{g} / 10 \mu \mathrm{l}$; IDT) and $0.5 \mu \mathrm{l}$ of Tetramethylrhodamine isothiocyanate conjugated $4.4 \mathrm{kDa}$ dextran (SIGMA, $10 \mathrm{mg} / \mathrm{ml}$ in $\mathrm{H}_{2} \mathrm{O}$ ). The $5 \mu \mathrm{l}$ of CRISPR-Cas9 RNP microinjection solution was incubated for 5-10 $\mathrm{min}$ at room temperature, and then dispensed into six microinjection needles. Silicon oil (ShinEtsu Co., Ltd., Tokyo, Japan), a laser absorbent (WF-25, Nepa Gene) and a UV absorbent (A-1428, TESK Co., Ltd., Tokyo, Japan) were added to the glass needle. The CRISPR-Cas9 RNP solution was injected into unilocular sporangia using an LTM-1000 laser thermal microinjector (Nepa Gene).

A similar protocol was used for the experiments that simultaneously targeted APT and MAS1, except that two separate crRNA/tracrRNA mixtures were made by mixing $0.5 \mu \mathrm{l}$ of crRNA (either gAPT1 or Mas1-C), $0.5 \mu \mathrm{l}$ of tracrRNA and $1.4 \mu \mathrm{l}$ of microinjection buffer, heating to $95^{\circ} \mathrm{C}$ and cooling and then adding $0.4 \mu \mathrm{l}$ of Cas9. The two mixes were pooled and added to $0.4 \mu \mathrm{l}$ of Rhodamine conjugated $4.4 \mathrm{kDa}$ dextran $\left(10 \mathrm{mg} / \mathrm{ml}\right.$ in $\left.\mathrm{H}_{2} \mathrm{O}\right)$. This solution was then treated as described above for microinjection. Stock solutions were as described above unless stated otherwise.

Droplet Digital Polymerase Chain Reaction Assays to Detect CRISPR-Cas9-induced indel mutations

Indel detection was carried out using between four and $125 \mathrm{ng}$ of total DNA on a QX200 Droplet Digital PCR System with 5(6)-carboxyfluorescein (FAM) and hexachloro-fluorescein (HEX) labelled oligonucleotide probes (Bio-Rad, Hercules, CA). Oligonucleotide primers and probes (Supplementary Table S1) were obtained from Bio-Rad. ddPCR reactions were carried out by Ingénierie et Analyse en Genome Editing (IAGE, Montferriez sur lez, France), essentially as described previously (Mignerot et al., 2019). A QX200 Droplet Generator (Bio-Rad) was used to distribute PCR components to individual reaction vessels. Droplets were generated by combining $70 \mu \mathrm{l}$ of droplet generation oil with $22 \mu \mathrm{l}$ of the PCR mix and $40 \mu \mathrm{l}$ of resulting droplet reaction was subjected to amplification. The cycling conditions for the PCR reaction included an initial incubation for $10 \mathrm{~min}$ at $95^{\circ} \mathrm{C}$ followed by 40 cycles of $94^{\circ} \mathrm{C}$ for $30 \mathrm{~s}$ and $55^{\circ} \mathrm{C}$ for $60 \mathrm{~s}$. Amplified plates were transferred to a Droplet Reader (Bio-Rad) and the digital PCR data were analysed with the provided Quanta Soft analytical software suite.

PCR detection of chromosomal mutations 
Mutations at target genes, induced by the introduction of CRISPR-Cas9 RNPs, were detected by PCR amplification and Sanger sequencing. The PCR primers were the same as those used for the in vitro cleavage assays (Supplementary Table S1).

Screen for off-target mutations

The genome of the 2-FAR mutant strain Ex1-1 was sequenced on an Illumina NovaSeq6000 platform (Génome Québec, Montréal, Canada), generating $34.5 \mathrm{~Gb}$ of sequence data, corresponding to $114,273,2832 \times 150 \mathrm{bp}$ paired-end reads (SRA accession number SRR12847952). The sequence reads were cleaned using Trimmomatic (Bolger et al., 2014) (parameters: --q 28, --length 50, --stringency 6, --max_n 3, --trim-n) and mapped against the Ec32 reference genome (version v2, available at Orcae; Sterck et al., 2012) using the BurrowsWheeler Aligner BWA-MEM (Li, 2013). Variants were called using the HaplotypeCaller function of GATK (McKenna et al., 2010). Potential off-target sites were predicted using CRISPOR (Haeussler et al., 2016) and searches for mutations at potential off-target sites were carried out using both the table of variants and by manual visualisation of the genomic regions using the Integrative Genomics Viewer (IGV; Thorvaldsdóttir et al., 2013).

In addition, the Ex1-1 resequencing data was used to carry out a genome-wide screen for variants that could potentially have arisen due to off-target activity. Because the Ectocarpus reference strain (Ec32) was sequenced in 2007 and has been maintained in culture since that time, filters were applied to exclude variants corresponding to either spontaneous mutations or sequencing errors. For this, we compared the Ex1-1 genome data, plus those of 19 other inhouse sequenced mutant strains, to the Ectocarpus reference genome (strain Ec32). We then eliminated any variants that were detected in both Ex1-1 and at least one of the 19 other strains (i.e. corresponding to putative shared spontaneous mutations). Two variants were considered to be identical if they occurred within a window of $10 \mathrm{bp}$ because the variant detection pipeline did not always locate identical variants to exactly the same position in the genome (for example, for small deletions or when the variant was located within a homopolymeric region). We also only considered positions with between $40 \mathrm{x}$ and $160 \mathrm{x}$ coverage and eliminated variants close to sequence gaps (runs of Ns). These latter filters were applied to eliminate sequence errors due to low coverage, aberrant mapping to repeated regions or poor quality sequence.

\section{Results}

Selection of target genes for mutagenesis 
To facilitate the identification of mutant individuals, we focused on two genes that have been developed as positive selection systems in other algal species (Ferenczi et al., 2017; Serif et al., 2018). The two genes were ADENINE PHOSPHORIBOSYL TRANSFERASE (APT), which, when mutated, has been shown to confer resistance to 2-Fluoroadenine (2-FA, Fig. 1a), and FK501BINDING-PROTEIN 12 (FKBP12), which confers resistance to rapamycin when mutated. The Ectocarpus species 7 APT orthologue (LocusID Ec-28_000520) was identified by reciprocal blasts against the Ectocarpus species 7 reference genome (available via the ORCAE database; Sterck et al., 2012; https://bioinformatics.psb.ugent.be/orcae/overview/EctsiV2), using both the Physcomitrella patens and the Phaeodactylum tricornutum APT genes as queries. Alignment of the three amino acid sequences confirmed conservation of the phosphoribosyl transferase domain in the Ectocarpus species 7 APT orthologue (Fig. 1b). A similar strategy (but employing orthologous sequences from Chlamydomonas reinhardtii and Saccharomyces cerevisiae as queries) was used to identify the Ectocarpus species 7 FKBP12 gene (LocusID Ec-12_005100; Fig. 1c). crRNAs were designed to target the first and third exons of the APT gene (Fig. 1d) and the second exon of the FKBP12 gene (Fig. 1e). CRISPR-Cas9 complexes carrying these crRNAs were shown to be active in an in vitro cleavage assay using PCR-amplified fragments of the targeted DNA regions (Fig. 1f).

Delivery of Cas9-RNPs to Ectocarpus species 7 cells

Given the absence of a genetic transformation system for Ectocarpus species 7, the objective of this study was to develop a targeted mutagenesis approach based on direct introduction of CRISPR-Cas9 RNPs. Two CRISPR-Cas9 RNP delivery methodologies were evaluated: biolistics and microinjection.

Gametes represent an interesting target material for biolistic delivery of CRISPR-Cas9 RNP complexes because they are single cells and they lack cell walls, facilitating entry of biolistic beads. In single-sex cultures of Ectocarpus species 7 gametophytes, released gametes develop parthenogenetically to produce haploid partheno-sporophytes (Fig. 2a). We observed that partheno-sporophyte germlings survived for several months on solidified, seawater-based medium (Fig. 2b), making this system suitable for the development of a biolistic delivery approach based on shooting gamete cells and subsequently recovering the derived parthenosporophytes. Initial test experiments showed that biolistic delivery allowed AF488-labelled 10 $\mathrm{kDa}$ Dextran to be loaded into both gametophyte (Fig. 2c) and gamete cells (Fig. 2d) indicating the feasibility of delivering macromolecular complexes such as CRISPR-Cas9 RNPs using this approach. 
For the microinjection approach, we targeted immature unilocular sporangia because these structures contain a syncytium of multiple nuclei that will later become uni-spores, the initial cell of the gametophyte generation (Fig. 2a). Laser-assisted thermal-expansion microinjection was used to deliver macromolecules to these structures because the cell wall and high turgor pressure of Ectocarpus species 7 cells make them hard to microinject with conventional techniques. As with the biolistic approach, fluorescently-labelled markers were used to confirm that the microinjection approach allowed delivery of macromolecular complexes to immature unilocular sporangia (Fig. 2j,k).

\section{Droplet digital PCR detection of TM events}

As a first step to detect and quantitate TM events, we designed a drop-off ddPCR assay (Findlay et al., 2016) based on mutation of FKBP12 (Figs. 1e, 3a). The biolistic approach was first tested on gametophytes, as we assumed that the larger size of their cells (20 $\mu \mathrm{m}$ compared to about 4 $\mu \mathrm{m}$ for gametes; Peters et al., 2008; Lipinska et al., 2015) would lead to higher rates of intracellular RNP delivery. Following biolistic delivery using various combinations of CRISPRCas9 RNP load, rupture pressure and target distance, DNA was extracted from the entire target material for each biolistic shot and ddPCR was used to estimate the frequency of TM events. This approach detected a low but significant level of TM events in six out of a total of 14 experiments (Fig. 3b). These experiments indicated that CRISPR-Cas9 RNPs had been introduced into a subset of the Ectocarpus species 7 gametophyte cells by the biolistic delivery method and that they were active in vivo, inducing modifications at their target site in the FKBP12 gene. ddPCR experiments were only carried out for mutations in the FKBP12 gene and were not used to analyse mutations in the APT gene.

Isolation of mutant Ectocarpus species 7 individuals following biolistic delivery

The ddPCR experiments indicated that TM events were only induced in a small subset of the total population of cells targeted in the biolistic experiments. To isolate non-chimeric, mutant individuals, we therefore developed a positively-selectable marker system and targeted a single cell stage, gametes. Wild type gametes were allowed to develop parthenogenetically in the presence of either 10 to $20 \mu \mathrm{M} 2-\mathrm{FA}$ or $15 \mu \mathrm{M}$ rapamycin to test the effectiveness of the two molecules as a selection system. These experiments showed that 10 to $20 \mu \mathrm{M}$ 2-FA completely inhibited growth of wild type Ectocarpus (Supplementary Fig. S1). In contrast, growth of parthenogenetic gametes was not reliably inhibited in the presence of rapamycin, probably at least partially due to breakdown of the antibiotic during culture. Based on these experiments, 
we decided to introduce CRISPR-Cas9 RNPs that targeted the APT gene. Biolistic experiments were then carried out using dense preparations of gametes (between about 40 and 60 million gametes per $60 \mathrm{~mm}$ plate) that had settled on an agar surface and CRISPR-Cas9 RNPs loaded with one of two crRNAs (either gAPT1 or gAPT2) targeting the first or the third exon of the Ectocarpus species 7 APT gene (Fig. 4a). Two days after bombardment, the culture medium was supplemented with $20 \mu \mathrm{M} 2$-FA and a small number of 2-FAR partheno-sporophytes developed in the Petri dishes after four to six weeks in culture (see Fig. 4b for an experiment using gAPT1). Three out of eight gAPT1 and two out of three gAPT2 experiments yielded 2-FAR algae (Fig. 4a and see the single crRNA experiments listed in Supplementary Table S2). DNA was isolated from all of the 2-FAR individuals for high fidelity PCR amplification, cloning and sequencing of the $A P T$ locus. This revealed the occurrence of targeted mutagenesis at the expected gAPT1 (Fig. 4c) and gAPT2 (Fig. 4d) CRISPR-Cas9 RNP cut sites, resulting in functional knock-outs of the Ectocarpus species 7 APT gene. All the 2-FAR individuals from the gAPT1 experiments had an additional adenine residue inserted between positions 520,479 and 520,480, three nucleotides before the PAM, inducing a frame shift in the coding sequence of the APT gene. The 2-FAR individuals from the gAPT2 experiments had deletions of one or four nucleotides three nucleotides before the PAM, which also resulted in frame shifts.

Isolation of mutant Ectocarpus species 7 individuals following microinjection of unilocular sporangia

We next determined whether it was possible to isolate individuals with TM events in the APT gene following laser-assisted thermal-expansion microinjection of unilocular sporangia with gAPT1 CRISPR-Cas9 RNP. Two unilocular sporangia were injected with gAPT1 CRISPR-Cas9 RNP at the 8-32 nucleate stage (Fig. 5a). The unilocular sporangia developed to maturity and released their uni-spores five days after microinjection. Four days after uni-spore release, 2-FA was added to the half-strength PES seawater medium to a final concentration of $20 \mu \mathrm{M}$. After a further seven days, 11 2-FAR individuals were detected and isolated. These individuals were transferred to fresh medium containing $20 \mu \mathrm{M}$ 2-FA in multiwell plates along with wild type gametophytes as a control (Fig. 5b). PCR amplification and Sanger sequencing of the region of exon 1 of the APT gene targeted by the gAPT1 CRISPR-Cas9 RNP showed that all 11 individuals carried the same mutation, an inserted adenine residue between nucleotides 520,479 and 520,480, at the site targeted by gAPT1 (Fig. 5c,d, Supplementary Table S2). Following meiotic division of the mother cell in a developing unilocular sporangium, the four daughter cells undergo several mitotic divisions to produce at least 100 meio-spores per unilocular sporangium (Knight, 1929; Peters et al., 2008). This phenomenon has been reported in diploid 
sporophytes but a similar process occurs in the unilocular sporangia of partheno-sporophytes. It is therefore possible that some of the mutant individuals were clonally derived from the same TM event but at least two mutation events must have occurred (one in each unilocular sporangium). Note also that the inserted adenine residue was the same mutation as had been previously detected following biolistic delivery of gAPT1 CRISPR-Cas9 RNP (Fig. 3c). This experiment demonstrated that CRISPR-Cas9 RNPs enter the nuclei of developing uni-spores following microinjection into unilocular sporangia, where they efficiently induce targeted mutation of the algal genome. The absence of false positive 2-FAR individuals indicated that 2FA treatment selected mutant individuals more efficiently in the microinjection experiments than in the biolistic experiments, possibly because the selection system is more effective when applied to a small number of individuals (up to about 500 for the microinjection experiments compared with many thousands for the biolistic experiments).

Simultaneous creation of double mutants potentially allows the mutation of any targeted locus

The above experiments demonstrated that it is possible to isolate individuals with targeted mutations provided that a positive selection system is available for the induced mutants. However, to develop an effective reverse genetic methodology, it was necessary to extend this approach so that it could be applied to any selected target gene. For this, we determined whether it was possible to isolated double mutants affected simultaneously at a positively selectable locus and at a second, target gene. Biolistic delivery was used to introduce mixtures of CRISPR-Cas9 RNPs carrying two different crRNAs, either targeting two different regions of the $A P T$ gene or simultaneously targeting APT plus a second gene (which was FKBP12 for these test experiments). Eleven biolistic shots were carried out using different combinations of pairs of crRNAs (Fig. 6, Supplementary Table S2). These experiments allowed the isolation of 172 FAR individuals, including two individuals that were mutated at two independent sites. The first individual carried a double mutation in the APT gene, corresponding to the sites targeted by gAPT2 and gAPT3, whereas the second individual carried mutations at the targeted sites in both the APT and the FKBP12 gene (Fig. 6). In both cases, the mutant individuals were isolated solely based on their resistance to 2-FA. Analysis of the apt fkbp12 double mutant in culture showed that the morphology of the partheno-sporophyte generation was normal and that the strain was fully fertile, producing both plurilocular and unilocular sporangia (Supplementary Fig. S2). Moreover, gametophytes derived from uni-spores produced by the apt fkbp12 parthenosporophyte were also morphologically normal and fertile, producing plurilocular gametangia (Supplementary Fig. S2). Therefore, mutation of the APT gene did not appear to have any phenotypic effect on either development or reproduction. This experiment demonstrated the 
feasibility of applying the methodology to any target gene in the Ectocarpus genome (with the proviso that the mutation should not be lethal, at least when haploid strains are being mutagenised).

To further validate the methodology, CRISPR-Cas9 RNPs carrying crRNAs directed against APT (gAPT1) and a second target gene VANADIUM-DEPENDENT BROMOPEROXIDASE (VBPO, locusID Ec-28_003320; crRNA vBPO-ex6-228f) were simultaneously delivered into gamete cells using the biolistic methodology. Two 2-FAR individuals were isolated from five experiments. One of these individuals was mutated at both the APT target site and the target site in the VBPO gene (Fig. 6, Supplementary table S2). These experiments demonstrated that double mutants could be reproducibly obtained using biolistic delivery.

To demonstrate that double mutants could also be obtained using the microinjection approach, 25 unilocular sporangia were injected with a mixture of CRISPR-Cas9 RNPs carrying gAPT1 and a crRNA (Mas1-C) directed against the MASTIGONEME1 gene (MAS1, Ec-04_001260), which is predicted to encode a mastigoneme protein. Thirteen of these unilocular sporangia released their uni-spores. Growth of these uni-spores on 2-FA resulted in the isolation of 22 2-FAR mutants from five different unilocular sporangia. PCR amplification and sequencing of the target sites of the $A P T$ and MAS1 genes in 13 of these mutants identified nine individuals that carried mutations in both genes (Fig. 6, Supplementary Table S2). Note, however, that all 13 2-FAR individuals were derived from the same injected unilocular sporangium so we cannot rule out the possibility that some of the mutant individuals were clonally derived from the same TM event.

\section{Efficiency of CRISPR-Cas9-mediated gene mutation}

The results of all of the experiments described in the two previous sections (Supplementary table S2) were analysed to estimate how efficiently the two methodologies, biolistics and microinjection, generated mutant individuals. Analysis of the experiments in which a single type of CRISPR-Cas9 RNP was introduced into Ectocarpus cells indicated that $33.3 \%$ and $18.2 \%$ of biolistic or microinjection experiments (where an experiment is either one biolistic shot or one injected unilocular sporangium), respectively, resulted in the isolation at least one apt mutant (Supplementary Table S2). The percentages of 2-FAR individuals that carried a mutation in the APT gene in these experiments was $46.2 \%$ and $100 \%$, for the biolistic and microinjection approaches, respectively. The average number of apt mutants obtained per experiment was 0.4 and 1.0 for the biolistic and microinjection methodologies, respectively. 
For the biolistic experiments that involved simultaneous introduction of two different CRISPRCas9 RNPs, we detected apt mutants in 50.0\% (eight out of 16) of the experiments. Of the 14 apt mutants identified, 21.4\% (three individuals) were double knockouts. Double knockouts were detected in $18.8 \%$ of the experiments (Supplementary Table S2). For the microinjection experiments that involved simultaneous introduction of two different CRISPR-Cas9 RNPs, we detected 2-FAR individuals in $20.0 \%$ of the experiments (five out of 25 experiments but note that 12 of the 20 unilocular sporangia that did not produce 2-FAR individuals did not release their uni-spores and, therefore, it was not possible to apply 2-FA selection). A total of 22 2-FAR individuals were isolated from the 25 experiments ( 0.9 per experiment on average). Sequence analysis of 13 of the 2-FAR individuals isolated from one of these experiments demonstrated that $31 \%$ (four individuals) were only mutated at the APT locus, whereas $69 \%$ (nine individuals) carried mutations at both the APT and MAS1 loci (Supplementary Table S2).

\section{Off-target mutations}

To estimate the frequency of off-target mutations, the genome of one of the apt mutants (Ex1-1; Fig. 4) was resequenced using an Illumina platform and the sequence data was analysed for evidence of mutations at potential off-target sites for the crRNA gAPT1 predicted by CRISPOR (Haeussler et al., 2016). No mutations were detected at any of the five potential off-target sites (Supplementary Table S3), indicating that the approach used does not induce a high frequency of off-target mutations.

In addition, we carried out a genome-wide analysis of variants in the genome of the Ex1-1 mutant (see Methods section for details). This analysis detected 56 variants compared to the Ectocarpus reference genome (Supplementary Table S4). Many of these variants were located in microsatellites, consistent with them corresponding to spontaneous mutations. Alignment of the variant regions with the gAPT1 crRNA indicated that none of them were in sequence contexts that would have been consistent with off-target effects of the CRISPR-Cas9 RNP (Supplementary Table S4). Conversely, 243 regions with weak similarity to gAPT1 (plus its PAM sequence) were detected by a very low stringency Blast search against the genome and none of these matching sequences were located within $400 \mathrm{bp}$ of a sequence variant. These analyses therefore supported our conclusion that off-target mutations were extremely rare or absent.

\section{Discussion}


This study has demonstrated the feasibility of using direct introduction of CRISPR-Cas9 RNPs into brown algal cells to induce targeted mutations. In particular, with the demonstration that induced, targeted mutations in the APT gene can be used to select for individuals carrying a mutation at a second targeted locus, it is now theoretically possible to mutate any selected gene in the Ectocarpus genome. One limiting factor may be lethality associated with mutation of essential genes, given that both of the delivery methods described here use haploid target cells. However, even for these genes, it may be possible to recover non-null mutations that nonetheless exhibit informative phenotypes. Moreover, in the future it should be feasible to build on the methodologies described here to develop a protocol that employs diploid cells, such as the mito-spores produced by diploid sporophytes for example.

As far as the efficiency of the two methods presented here is concerned, 2-FAR individuals were obtained in $52 \%$ and $19 \%$ of biolistic and microinjection experiments, respectively, and, on average, we obtained 1.2 and 0.9 2-FAR individuals per experiment, respectively. The limited number of experiments did not allow us to obtain a precise measurement of the percentage of double knockout mutants but this was estimated at $18 \%$ and $69 \%$ of the apt mutants isolated after introduction of two different CRISPR-Cas9 RNPs by either biolistics or microinjection, respectively. The methodology presented here is therefore sufficiently efficient and reproducible for it to be used reliably to isolate mutations for any selected Ectocarpus gene.

There are several advantages to directly introducing CRISPR-Cas9 RNPs into target cells rather than using an in vivo expression system. First, it is not necessary that a transformation protocol be available for the target species. Second, the methodology is relatively easy to employ because it does not require the construction of complex transformation vectors. Third, following direct introduction, the CRISPR-Cas9 RNPs are only present transiently in the cell and therefore the frequency of off-target mutations is expected to be lower than if CRISPR-Cas9 RNPs are expressed over an extended period (Kim et al., 2014). This expectation was supported by the absence of mutations at potential off-target sites in the apt mutant Ex1-1. Finally, as pointed out by Serif et al. (2018), the above advantages, in particular the absence of a need for genetic transformation, mean that it should be relatively easy to adapt such methodology for use in related species. Specifically, it should be possible to adapt the methodology described here for other brown algal species, provided that a suitable protocol is available to deliver CRISPR-Cas9 RNPs into cells and that the $A P T$-based selection system used is effective in the new species. It may even be possible to circumvent the need for a selection system if microinjection can be used to deliver CRISPR-Cas9 RNPs to well-identified cells that can be isolated post-injection. 
The availability of an effective reverse genetics tool for Ectocarpus opens up multiple avenues for both fundamental and applied brown algal research. In the fundamental domain, this tool will allow the brown algal community to investigate the functions of multiple genes implicated in diverse aspects of brown algal biology, particularly those associated with novel features or features of broad phylogenetic interest such as the emergence of complex multicellularity, the evolution of complex, highly flexible cell walls, haploid phase sex determination, novel metabolic processes or interactions with both biotic and abiotic factors (Michel et al., 2010a; Cock et al., 2014; Ahmed et al., 2014; Cock \& Collén, 2015; Dittami et al., 2016; Strittmatter et al., 2016; Coelho \& Cock, 2020). From a more applied point of view, the availability of reverse genetics will greatly enhance the usefulness of Ectocarpus as a model organism to understand brown algal traits that are relevant to seaweed aquaculture such as genetic factors underlying growth and biomass production (Avia et al., 2017), metabolic pathways influencing biomolecule content (La Barre et al., 2010; Michel et al., 2010a,b) and the defence mechanisms that control and prevent disease (Gachon et al., 2010). In addition, the ability to target specific genes may potentially make Ectocarpus itself interesting for biotechnological applications, for example using the organism as a cell factory. In this context, the availability of mutant strains that have lost the ability to adhere to substrata (Godfroy et al., 2017) may be of interest for the cultivation of this species in bioreactors.

Finally, in addition to adapting the existing CRISPR-Cas9-based system to other brown algae, another important objective for the future will be to extend and improve the CRISPR-Cas9based tools available for Ectocarpus. For example, the targeted mutations reported here presumably result from the action of the non-homologous end joining repair pathway. The involvement of this pathway could be exploited to develop gene knock-in strategies using simultaneous delivery of donor DNA (Suzuki et al., 2016). Likewise, it will be interesting to test the effectiveness of alternatives to the Cas9 nuclease (Zetsche et al., 2015; Pausch et al., 2020) and, in the longer-term, to adapt more sophisticated methodologies such as homology-mediated gene editing (Savić et al., 2019) or prime editing (Anzalone et al., 2019) for use in this key model organism.

\section{Acknowledgements}

We would like to thank Anne De Cian and Fayza Daboussi for advice on the CRISPR system and for supplying Cas9 proteins and Dominique Marie for help with flow cytometry analysis of Ectocarpus gametes. This work was supported by the Région Bretagne's Stratégie d'Attractivité 
Durable (SAD) program (grant to support YB), the Marine Alliance for Science and Technology Scotland, a UK Natural Environment Research Council International Opportunities Fund Pumppriming Award (NE/L013223/1), the European Research Council (SexSea grant agreement 638240), the European Union's Horizon 2020 research and innovation programme ASSEMBLE Plus project (grant agreement No 730984), the Agence Nationale de la Recherche projects Epicycle and Idealg (ANR-19-CE20-0028-01 and ANR-10-BTBR-04-01), the Centre National de la Recherche Scientifique, the Gordon and Betty Moore Foundation program Symbiosis in Aquatic Systems Initiative (grant agreement 4546891618), Sorbonne University and the European Union COST program Phycomorph. We thank the Institut Français de Bioinformatique and the Roscoff Analysis and Bioinformatics for Marine Science platform ABiMS (http://abims.sb-roscoff.fr) for providing computing and data storage resources.

\section{Author Contributions}

YB conceived the project and carried out the biolistic experiments with help from DS and MR. $\mathrm{MH}, \mathrm{TM}$ and $\mathrm{CN}$ developed the microinjection approach and carried out the microinjection experiments. CC and DS explored and optimised delivery methodologies. OG and YB carried out the variant analysis. TM, CN, CMMG, SMC and JMC supervised the project. YB and JMC wrote the manuscript with input from all the authors. 


\section{References}

Ahmed S, Cock JM, Pessia E, Luthringer R, Cormier A, Robuchon M, Sterck L, Peters AF, Dittami SM, Corre E, et al.2014. A Haploid System of Sex Determination in the Brown Alga Ectocarpus sp. Curr Biol 24: 1945-1957.

Anzalone AV, Randolph PB, Davis JR, Sousa AA, Koblan LW, Levy JM, Chen PJ, Wilson C, Newby GA, Raguram A, et al.2019. Search-and-replace genome editing without double-strand breaks or donor DNA. Nature 576: 149-157.

Arun A, Coelho SM, Peters AF, Bourdareau S, Pérès L, Scornet D, Strittmatter M, Lipinska AP, Yao H, Godfroy 0, et al.2019. Convergent recruitment of TALE homeodomain life cycle regulators to direct sporophyte development in land plants and brown algae. eLife 8: e43101. Avia K, Coelho SM, Montecinos AE, Cormier A, Lerck F, Mauger S, Faugeron S, Valero M, Cock JM, Boudry P. 2017. High-density genetic map and identification of QTLs for responses to high temperature and low salinity stresses in the model alga Ectocarpus sp. Scientific Reports 7: 43241.

Bolger AM, Lohse M, Usadel B. 2014. Trimmomatic: a flexible trimmer for Illumina sequence data. Bioinformatics (Oxford, England) 30: 2114-2120.

Bothwell JH, Marie D, Peters AF, Cock JM, Coelho SM. 2010. Role of endoreduplication and apomeiosis during parthenogenetic reproduction in the model brown alga Ectocarpus. New Phytol 188: 111-21.

Bourdareau S, Tirichine L, Lombard B, Loew D, Scornet D, Wu Y, Coelho SM, Cock JM. 2021. Histone modifications during the life cycle of the brown alga Ectocarpus. Genome Biology 22: 12 .

Cho SW, Lee J, Carroll D, Kim J-S, Lee J. 2013. Heritable gene knockout in Caenorhabditis elegans by direct injection of Cas9-sgRNA ribonucleoproteins. Genetics 195: 1177-1180.

Chung IK, Beardall J, Mehta S, Sahoo D, Stojkovic S. 2011. Using marine macroalgae for carbon sequestration: a critical appraisal. Journal of Applied Phycology 23: 877-886.

Cock JM, Collén J. 2015. Independent emergence of complex multicellularity in the brown and red algae. In: Ruiz-Trillo I, Nedelcu AM, eds. Advances in Marine Genomics. Evolutionary transitions to multicellular life. Springer Verlag, 335-361.

Cock JM, Godfroy 0, Macaisne N, Peters AF, Coelho SM. 2014. Evolution and regulation of complex life cycles: a brown algal perspective. Curr Opin Plant Biol 17: 1-6.

Cock JM, Sterck L, Rouzé P, Scornet D, Allen AE, Amoutzias G, Anthouard V, Artiguenave F, Aury J, Badger J, et al.2010. The Ectocarpus genome and the independent evolution of multicellularity in brown algae. Nature 465: 617-621.

Coelho S, Cock J. 2020. Brown algal model organisms. Ann Rev Genet 54: 71-92.

Coelho SM, Scornet D, Rousvoal S, Peters NT, Dartevelle L, Peters AF, Cock JM. 2012. How to cultivate Ectocarpus. Cold Spring Harb Protoc 2012: 258-261.

Coleman MA, Goold HD. 2019. Harnessing synthetic biology for kelp forest conservation. Journal of Phycology 55: 745-751.

Coleman MA, Wernberg T. 2017. Forgotten underwater forests: The key role of fucoids on Australian temperate reefs. Ecology and Evolution 7: 8406-8418.

Concordet J-P, Haeussler M. 2018. CRISPOR: intuitive guide selection for CRISPR/Cas9 genome editing experiments and screens. Nucleic Acids Research 46: W242-W245.

Cormier A, Avia K, Sterck L, Derrien T, Wucher V, Andres G, Monsoor M, Godfroy 0, Lipinska A, Perrineau M-M, et al.2017. Re-annotation, improved large-scale assembly and establishment of a catalogue of noncoding loci for the genome of the model brown alga Ectocarpus. The New Phytologist 214: 219-232.

Dittami SM, Duboscq-Bidot L, Perennou M, Gobet A, Corre E, Boyen C, Tonon T. 2016. Hostmicrobe interactions as a driver of acclimation to salinity gradients in brown algal cultures. The ISME journal 10: 51-63.

Dittami S, Scornet D, Petit J, Ségurens B, Da Silva C, Corre E, Dondrup M, Glatting K, König R, Sterck L, et al.2009. Global expression analysis of the brown alga Ectocarpus siliculosus 
(Phaeophyceae) reveals large-scale reprogramming of the transcriptome in response to abiotic stress. Genome Biol 10: R66.

Duarte CM, Wu J, Xiao X, Bruhn A, Krause-Jensen D. 2017. Can Seaweed Farming Play a Role in Climate Change Mitigation and Adaptation? Frontiers in Marine Science 4: 100.

Fang Y, Cui L, Gu B, Arredondo F, Tyler BM. 2017. Efficient Genome Editing in the Oomycete Phytophthora sojae Using CRISPR/Cas9. Current Protocols in Microbiology 44: 21A.1.1-21A.1.26.

Farnham G, Strittmatter M, Coelho SM, Cock JM, Brownlee C. 2013. Gene silencing in Fucus embryos: developmental consequences of RNAi-mediated cytoskeletal disruption. J Phycol 49: 819-829.

Ferenczi A, Pyott DE, Xipnitou A, Molnar A. 2017. Efficient targeted DNA editing and replacement in Chlamydomonas reinhardtii using $C p f 1$ ribonucleoproteins and single-stranded DNA. Proceedings of the National Academy of Sciences of the United States of America 114: 13567-13572.

Findlay SD, Vincent KM, Berman JR, Postovit L-M. 2016. A Digital PCR-Based Method for Efficient and Highly Specific Screening of Genome Edited Cells. PloS One 11: e0153901. Gachon CM, Sime-Ngando T, Strittmatter M, Chambouvet A, Kim GH. 2010. Algal diseases: spotlight on a black box. Trends Plant Sci 15: 633-40.

Godfroy O, Uji T, Nagasato C, Lipinska AP, Scornet D, Peters AF, Avia K, Colin S, Mignerot L, Motomura T, et al.2017. DISTAG/TBCCd1 Is Required for Basal Cell Fate Determination in Ectocarpus. The Plant Cell 29: 3102-3122.

Gschloessl B, Guermeur Y, Cock J. 2008. HECTAR: a method to predict subcellular targeting in heterokonts. BMC Bioinf 9: 393.

Haeussler M, Schönig K, Eckert H, Eschstruth A, Mianné J, Renaud J-B, SchneiderMaunoury S, Shkumatava A, Teboul L, Kent J, et al.2016. Evaluation of off-target and ontarget scoring algorithms and integration into the guide RNA selection tool CRISPOR. Genome Biology 17: 148.

Heesch S, Cho GY, Peters AF, Le Corguillé G, Falentin C, Boutet G, Coëdel S, Jubin C, Samson G, Corre E, et al.2010. A sequence-tagged genetic map for the brown alga Ectocarpus siliculosus provides large-scale assembly of the genome sequence. New Phytol 188: 42-51.

Hirata R, Takahashi M, Saga N, Mikami K. 2011. Transient gene expression system established in Porphyra yezoensis is widely applicable in Bangiophycean algae. Marine Biotechnology (New York, N.Y.) 13: 1038-1047.

Jiang P, Qin S, Tseng CK. 2003. Expression of the lacZ reporter gene in sporophytes of the seaweed Laminaria japonica (Phaeophyceae) by gametophyte-targeted transformation. Plant Cell Reports 21: 1211-1216.

Kim S, Kim D, Cho S, Kim J, Kim J-S. 2014. Highly efficient RNA-guided genome editing in human cells via delivery of purified Cas9 ribonucleoproteins. Genome Research 24: 1012-1019. Klinger T. 2015. The role of seaweeds in the modern ocean. Perspect Phycol 2: 31-39. Knight M. 1929. Studies in the Ectocarpaceae. II. The life-history and cytology of Ectocarpus siliculosus, Dillw. Transaction of Royal Society LVI: 307-342.

Kroth PG. 2013. Getting a grip on genetic modification in brown algae. Journal of Phycology 49: 816-818.

La Barre S, Potin P, Leblanc C, Delage L. 2010. The halogenated metabolism of brown algae (Phaeophyta), its biological importance and its environmental significance. Mar Drugs 8: 9881010.

Li H. 2013. Aligning sequence reads, clone sequences and assembly contigs with BWA-MEM. arXiv:1303.3997 [q-bio].

Lipinska A, Cormier A, Luthringer R, Peters AF, Corre E, Gachon CMM, Cock JM, Coelho SM. 2015. Sexual dimorphism and the evolution of sex-biased gene expression in the brown alga Ectocarpus. Molecular Biology and Evolution 32: 1581-1597.

Macaisne N, Liu F, Scornet D, Peters AF, Lipinska A, Perrineau M-M, Henry A, Strittmatter M, Coelho SM, Cock JM. 2017. The Ectocarpus IMMEDIATE UPRIGHT gene encodes a member of a novel family of cysteine-rich proteins with an unusual distribution across the eukaryotes.

Development 144: 409-418. 
McHugh DJ. 2003. A guide to the seaweed industry. In: FAO, ed. FAO Fisheries Technical Paper No 441. Rome, Italy: FA0, pp. 1-105.

McKenna A, Hanna M, Banks E, Sivachenko A, Cibulskis K, Kernytsky A, Garimella K, Altshuler D, Gabriel S, Daly M, et al.2010. The Genome Analysis Toolkit: a MapReduce framework for analyzing next-generation DNA sequencing data. Genome Res 20: 1297-303.

Michel G, Tonon T, Scornet D, Cock JM, Kloareg B. 2010a. The cell wall polysaccharide metabolism of the brown alga Ectocarpus siliculosus. Insights into the evolution of extracellular matrix polysaccharides in Eukaryotes. New Phytol 188: 82-97.

Michel G, Tonon T, Scornet D, Cock JM, Kloareg B. 2010b. Central and storage carbon metabolism of the brown alga Ectocarpus siliculosus: insights into the origin and evolution of storage carbohydrates in Eukaryotes. New Phytol 188: 67-81.

Mignerot L, Nagasato C, Peters AF, Perrineau M-M, Scornet D, Pontheaux F, Djema W, Badis Y, Motomura T, Coelho SM, et al.2019. Unusual Patterns of Mitochondrial Inheritance in the Brown Alga Ectocarpus. Molecular Biology and Evolution 36: 2778-2789.

Mikami K. 2014. A technical breakthrough close at hand: feasible approaches toward establishing a gene-targeting genetic transformation system in seaweeds. Frontiers in Plant Science 5: 498.

Montecinos AE, Couceiro L, Peters AF, Desrut A, Valero M, Guillemin M-L. 2017. Species delimitation and phylogeographic analyses in the Ectocarpus subgroup siliculosi (Ectocarpales, Phaeophyceae). Journal of Phycology 53: 17-31.

Nagasato C, Tanaka A, Ito T, Katsaros C, Motomura T. 2017. Intercellular translocation of molecules via plasmodesmata in the multiseriate filamentous brown alga, Halopteris congesta (Sphacelariales, Phaeophyceae). Journal of Phycology 53: 333-341.

Nagasato C, Terauchi M, Tanaka A, Motomura T. 2015. Development and function of plasmodesmata in zygotes of Fucus distichus. Botanica Marina 58: 229-238.

Nymark M, Sharma AK, Sparstad T, Bones AM, Winge P. 2016. A CRISPR/Cas9 system adapted for gene editing in marine algae. Scientific Reports 6: 24951.

Oertel W, Wichard T, Weissgerber A. 2015. Transformation of Ulva mutabilis (Chlorophyta) by vector plasmids integrating into the genome. Journal of Phycology 51: 963-979.

Ortega A, Geraldi NR, Alam I, Kamau AA, Acinas SG, Logares R, Gasol JM, Massana R, Krause-Jensen D, Duarte CM. 2019. Important contribution of macroalgae to oceanic carbon sequestration. Nature Geoscience 12: 748-754.

Pausch P, Al-Shayeb B, Bisom-Rapp E, Tsuchida CA, Li Z, Cress BF, Knott GJ, Jacobsen SE, Banfield JF, Doudna JA. 2020. CRISPR-Cas $\Phi$ from huge phages is a hypercompact genome editor. Science (New York, N.Y.) 369: 333-337.

Peters AF, Marie D, Scornet D, Kloareg B, Cock JM. 2004. Proposal of Ectocarpus siliculosus (Ectocarpales, Phaeophyceae) as a model organism for brown algal genetics and genomics. J Phycol 40: 1079-1088.

Peters AF, Scornet D, Ratin M, Charrier B, Monnier A, Merrien Y, Corre E, Coelho SM, Cock JM. 2008. Life-cycle-generation-specific developmental processes are modified in the immediate upright mutant of the brown alga Ectocarpus siliculosus. Development 135: 1503-1512.

Ritter A, Dittami SM, Goulitquer S, Correa JA, Boyen C, Potin P, Tonon T. 2014.

Transcriptomic and metabolomic analysis of copper stress acclimation in Ectocarpus siliculosus highlights signaling and tolerance mechanisms in brown algae. BMC plant biology 14: 116.

Ritter A, Ubertini M, Romac S, Gaillard F, Delage L, Mann A, Cock JM, Tonon T, Correa JA, Potin P. 2010. Copper stress proteomics highlights local adaptation of two strains of the model brown alga Ectocarpus siliculosus. Proteomics 10: 2074-88.

Savić N, Ringnalda FC, Berk C, Bargsten K, Hall J, Jinek M, Schwank G. 2019. In vitro Generation of CRISPR-Cas9 Complexes with Covalently Bound Repair Templates for Genome Editing in Mammalian Cells. Bio-Protocol 9.

Serif M, Dubois G, Finoux A-L, Teste M-A, Jallet D, Daboussi F. 2018. One-step generation of multiple gene knock-outs in the diatom Phaeodactylum tricornutum by DNA-free genome editing. Nature Communications 9: 3924.

Starr RC, Zeikus JA. 1993. UTEX-The culture collection of algae at the University of Texas at 
Austin 1993 list of cultures. J Phycol 29 (Suppl.): 1-106.

Sterck L, Billiau K, Abeel T, Rouzé P, Van de Peer Y. 2012. ORCAE: online resource for community annotation of eukaryotes. Nat Methods 9: 1041.

Strittmatter M, Grenville-Briggs LJ, Breithut L, Van West P, Gachon CMM, Küpper FC. 2016. Infection of the brown alga Ectocarpus siliculosus by the oomycete Eurychasma dicksonii induces oxidative stress and halogen metabolism. Plant, Cell \& Environment 39: 259-271.

Suzuki K, Tsunekawa Y, Hernandez-Benitez R, Wu J, Zhu J, Kim EJ, Hatanaka F, Yamamoto M, Araoka T, Li Z, et al.2016. In vivo genome editing via CRISPR/Cas9 mediated homologyindependent targeted integration. Nature 540: 144-149.

Tarver JE, Cormier A, Pinzón N, Taylor RS, Carré W, Strittmatter M, Seitz H, Coelho SM, Cock JM. 2015. microRNAs and the evolution of complex multicellularity: identification of a large, diverse complement of microRNAs in the brown alga Ectocarpus. Nucl Acids Res 43: 63846398.

Thorvaldsdóttir H, Robinson JT, Mesirov JP. 2013. Integrative Genomics Viewer (IGV): highperformance genomics data visualization and exploration. Briefings in Bioinformatics 14: 178192.

Wahl M, Molis M, Hobday AJ, Dudgeon S, Neumann R, Steinberg P, Campbell AH, Marzinelli E, Connell S. 2015. The responses of brown macroalgae to environmental change from local to global scales: direct versus ecologically mediated effects. Perspect Phycol 2: 11-29. Zetsche B, Gootenberg JS, Abudayyeh O0, Slaymaker IM, Makarova KS, Essletzbichler P, Volz SE, Joung J, van der Oost J, Regev A, et al.2015. Cpf1 is a single RNA-guided endonuclease of a class 2 CRISPR-Cas system. Cell 163: 759-771.

Zhang Y, Jiang P, Gao J, Liao J, Sun S, Shen Z, Qin S. 2008. Recombinant expression of rt-PA gene (encoding Reteplase) in gametophytes of the seaweed Laminaria japonica (Laminariales, Phaeophyta). Science in China Series C: Life Sciences 51: 1116-1120. 


\section{Supplementary material}

\section{Supplementary figures}

Supplementary Fig. S1. Growth of partheno-sporophyte germlings is inhibited in the presence of 2-Fluoroadenine.

Supplementary Fig. S2. Normal morphology and reproduction of the apt fkbp12 double mutant.

\section{Supplementary tables}

Supplementary Table S1. Sequences of oligonucleotide primers and crRNAs used in this study.

Supplementary Table S2. Numbers of 2FAR individuals detected in each bioloistic or microinjection delivery experiment.

Supplementary Table S3. Predicted possible off-target sites for all the crRNAs used in this study

Supplementary Table S4. Genome-wide analysis of sequence variants in the apt mutant Ex1-1. 
Figures 
(a)

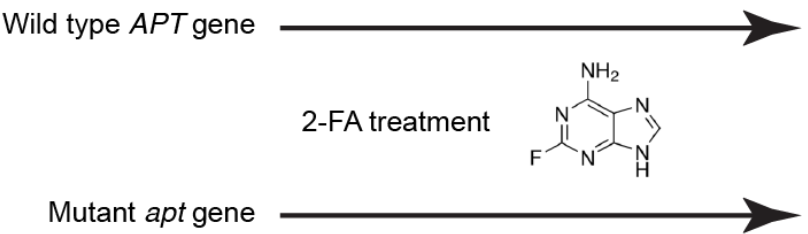

Mutant apt gene

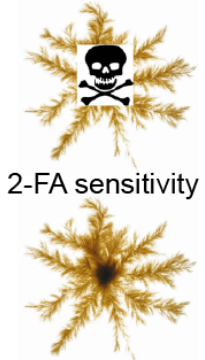

2-FA resistance

(b)

EC-28_000520.1 . . . . PtAPT MTTTNGSAAVLVSDKYAQDGDE. . . . AKEIAEYLPYFPFKGIPRFYDIGGFLYEPKVFQ PpAPT ….................

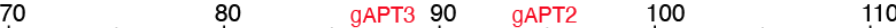

120

EC-28_000520.1 LAVK IFADRYRGMK I DS I GGFDARGF I LGPPVALALN I PFFMLRKKGKMPNV I DGAAYSK PtAPT K I VDVFVDRYREI GVDV I AGLDARGFVLGPP I ALALNKPF I MMRKKGKMPNSVSSDDYTT PPAPT DT I DI FVERYRDQKVDV I VGI EARGFI FGPP I ALA I GAKFVPMRKPRKLPGPV I REEYSL

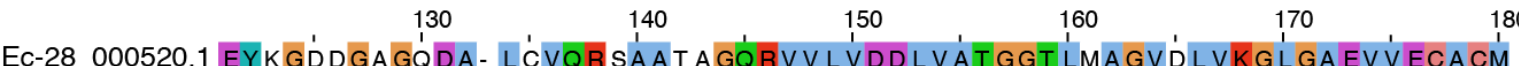
PtAPT $\quad$ EY...... GNRQGLTVQKDK I QKNHRVL I I DDLVATGGTLGSAVSLVKMLGGVVVECACV PPAPT EY...... GTDC- I EMHVGA I EKNERVV I VDDL I ATGGT LGAA I KLLDKVEAE I VECACL

$$
190 \quad 200,210,230
$$

EC-28_000520.1 I ELK.' . . . . . . . . . A A'LNGVGKLHER.' - HADVPVWSL' I SEN'I LTVK.' . . . . . . . . . GEESS* PIAPT VELKMFIDPPEESGLPSRKKLFAELGHHDVGVWGL I SEDI LTNKADLPQHYVDDGEEH* -

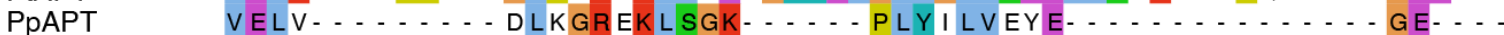

(c) 10 20 30 40 gFKB12-Ex2-23f 50 60

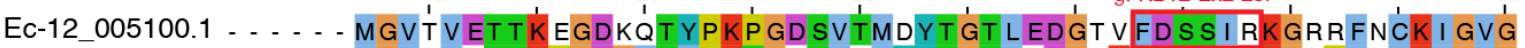
CrFKBP12 …. . MGVDVATTRPGDGV SFPKTGQTVFVHYTGT LTDGKKFDSSRDRGEP F SFRLGMG ScFKBP12 MSEV I EGNVK I DR I SPGDGATFPKT GDLVT I HYT GT LENGQKFD SSVDRGSPFQCN I GVG 70 80 90 100 110 EC-12 005100.1 QV I QGWDEGVPQMSLGEKA I LKCT SDYAYGPEGAGGV IPPNADL' I FEVELHA I NGQ'QGK * CrFKBP12 ScFKBP12 EV I KGWDEGVAQM SKGQRATLT I SHDFAYGPRG I PGV I PPSATLVFDVELLDYK* . . . QV I KGWDVG I PKLSVGEKARLT I PGPYAYGPRGFPGL I PPNSTLVFDVELLKVN* . . .

(d)

Ectocarpus APT (Ec-28_000520)

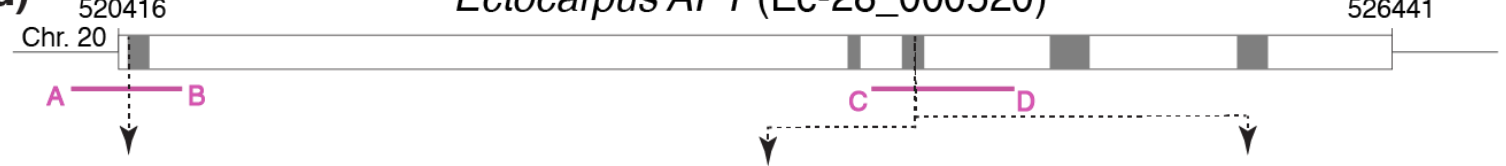

ATGGAGGAAACGTACATGCCAGATGGGCCA

ACGCTCGAGGCTTCATCCTCGGCCCGCCGGTGG

CCCGCCGGTGGCTCTCGCGCTCAACATCCGT GAPT GAPT3 gAPT2

(e)

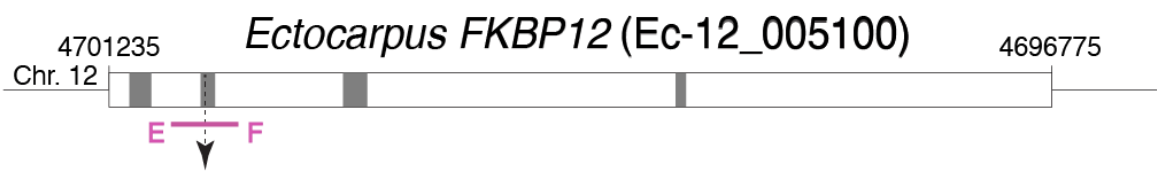

AACAGGTGTTCGACAGCTCCATCCGGAAGGGCA gFKB12-EX2-23f

(f)

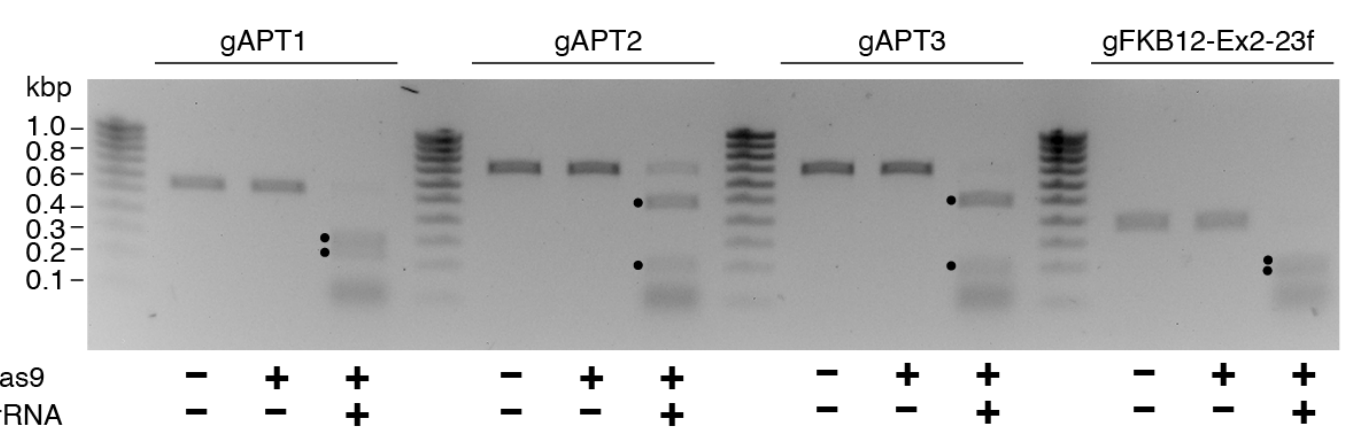


Fig. 1. Selection of target genes for CRISPR-Cas9-mediated mutagenesis and design of crRNAs. (a) Principle of the positive selection system using the APT marker gene, indicating the 2-FA resistance (2-FAR) phenotype of apt mutants. (b,c) Alignments of APT (b) and FKBP12 (c) protein sequences. Conserved amino acids are highlighted in colour, regions corresponding to crRNA target sites are indicated by red boxes. Pp, Physcomitrella patens; Pt, Phaeodactylum tricornutum; Cr, Chlamydomonas reinhardtii; Sc, Saccharomyces cerevisiae. (d,e) Schematic representations of the $A P T$ (d) and FKBP12 (e) genes. Open boxes correspond to the transcribed regions of the genes, grey boxes to coding sequence. Light grey arrows indicate the positions of target sequences for crRNAs together with their associated protospacer adjacent motifs (PAMs, in bold). Pink bars indicate the regions amplified to test the activity of CRISPR-Cas9 RNPs in vitro or to detect mutations by Sanger sequencing. PCR primers (pink letters) were: A, APT1-Fcrispor; B, APT1-R2-500bp; C, APT2-F; D, APT1-R2-675bp; E, FKBex-F; F, FKBex2-R (see Supplementary Table S1 for details). Chr. 20, chromosome 20; Chr. 12, chromosome 12. (f) In vitro activity tests of CRISPR-cas9 RNPs directed against target regions in the APT and FKBP12 genes. PCR amplicons containing the crRNA target sites were incubated with preassembled RNP complexes and the digestion products were then separated on a 1.5\% agarose gel (see Methods section for details). Black dots indicate digestion products. gAPT1, gAPT2, gFKB12-Ex2-23f, different crRNAs directed against the APT or FKBP12 genes. 


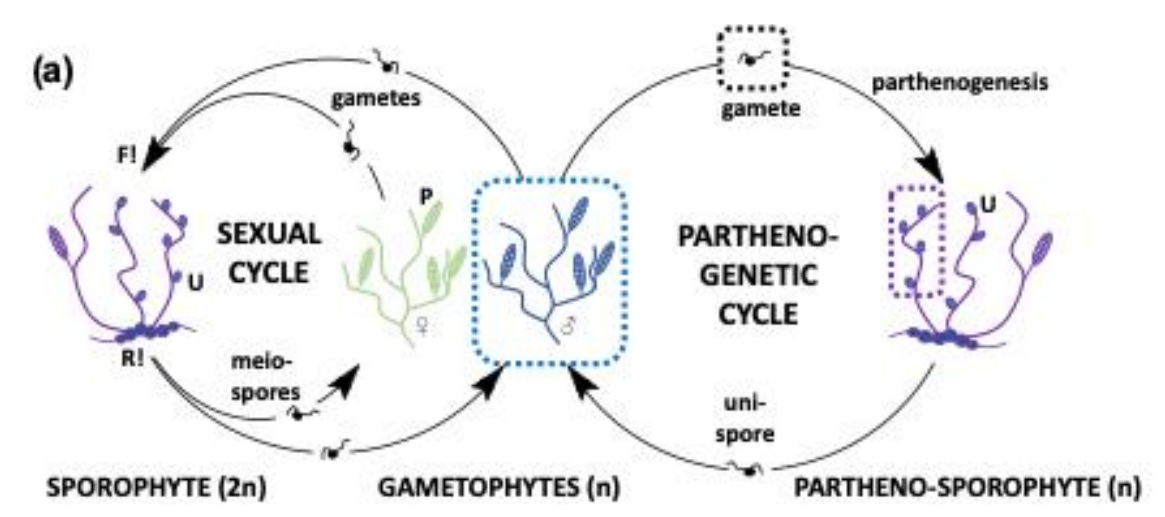

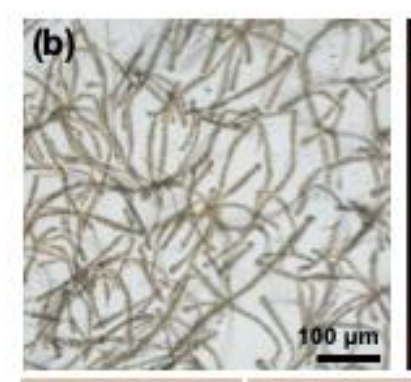
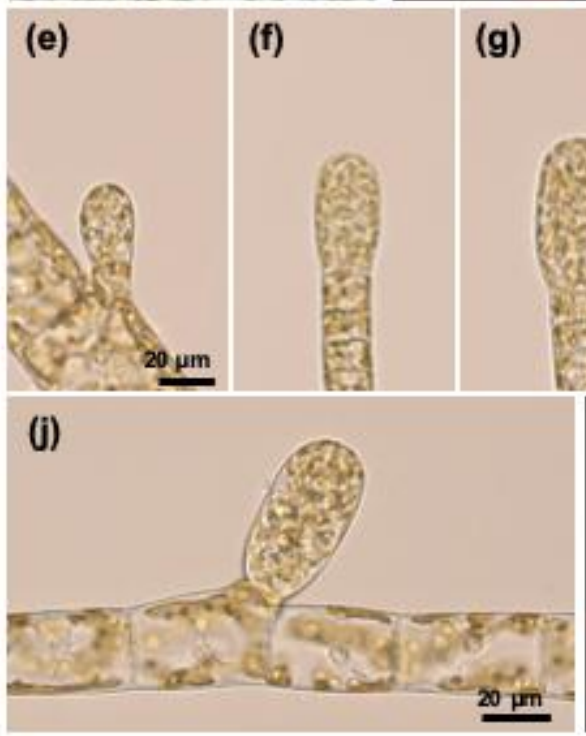

(f)

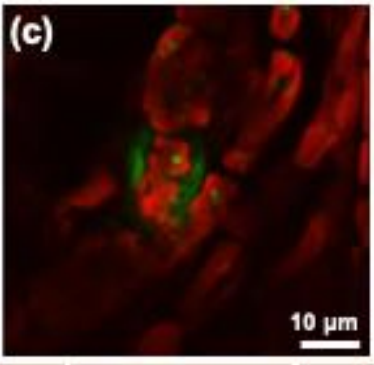

(g)

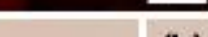

(h)

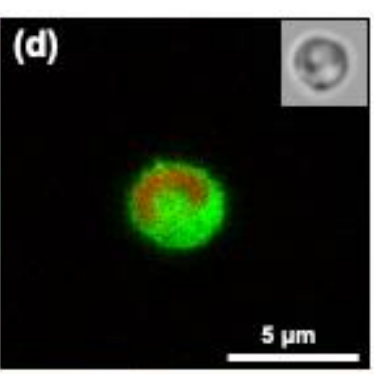

(i)

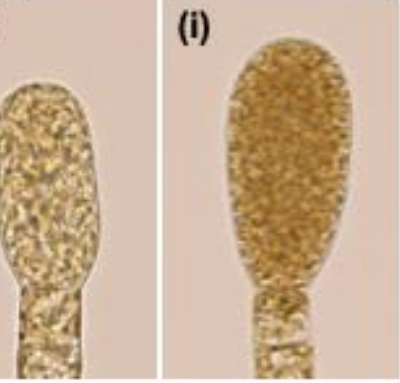

(k)

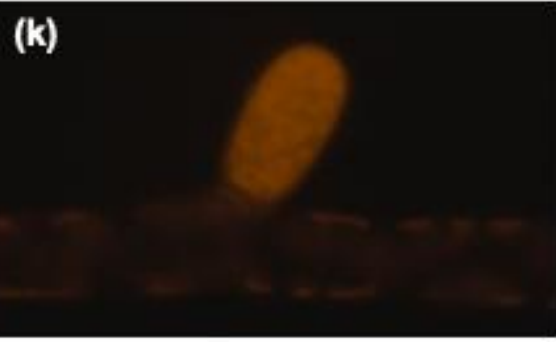

Fig. 2. Delivery of macromolecules into Ectocarpus species 7 cells by biolistics and microinjection. (a) Life cycle of Ectocarpus species 7. Meiosis (R!) occurs in unilocular sporangia (U) on the diploid sporophyte, producing meio-spores that develop into male and female gametophytes. Gametophytes produce gametes in plurilocular gametangia (P), which fuse (F!) to produce the diploid sporophyte and complete the sexual cycle (left side of the panel). Gametes can also develop parthenogenetically to produce haploid partheno-sporophytes, which produce unilocular sporangia $(\mathrm{U})$ that release spores to complete the parthenogenetic cycle (right side of the panel). We refer to the spores produced in the unilocular sporangia of partheno-sporophytes by the general term uni-spores because they are produced by non- 
standard meiotic events (either apomeiosis or a meiosis-like division following endoreduplication; Bothwell et al., 2010). Dashed boxes indicate the life stages subjected to CRISPR-Cas9 RNP delivery for ddPCR detection (blue, biolistic delivery to gametophytes) and gene knock-out (black, biolistic delivery to gametes; purple, microinjection of unilocular sporangia). (b) Ectocarpus species 7 partheno-sporophytes growing on 1.5\% seawater agar (one month after gamete settlement). (c,d) Merges of chlorophyll (red) and AF488-labelled 10 $\mathrm{kDa}$ Dextran (green) fluorescence signals illustrating intracellular biolistic delivery of macromolecules into gametophyte (c) and gamete (d) cells. The insert in $\mathrm{d}$ is a transmitted light image of the gamete. (e-i) Time series showing the development of a unilocular sporangium. (e) 8-16 nucleate stage. (f) 32 nucleate stage. (g) 64-128 nucleate stage. (h) 256 nucleate stage. (i) Fully mature (512 nucleate) unilocular sporangium. Microinjection was carried out at stages e to g. (j,k) Unilocular sporangium showing (red) fluorescence of microinjected rhodamine. 
(a)

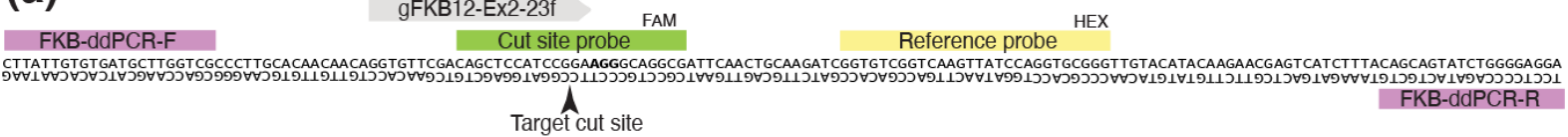

(b)

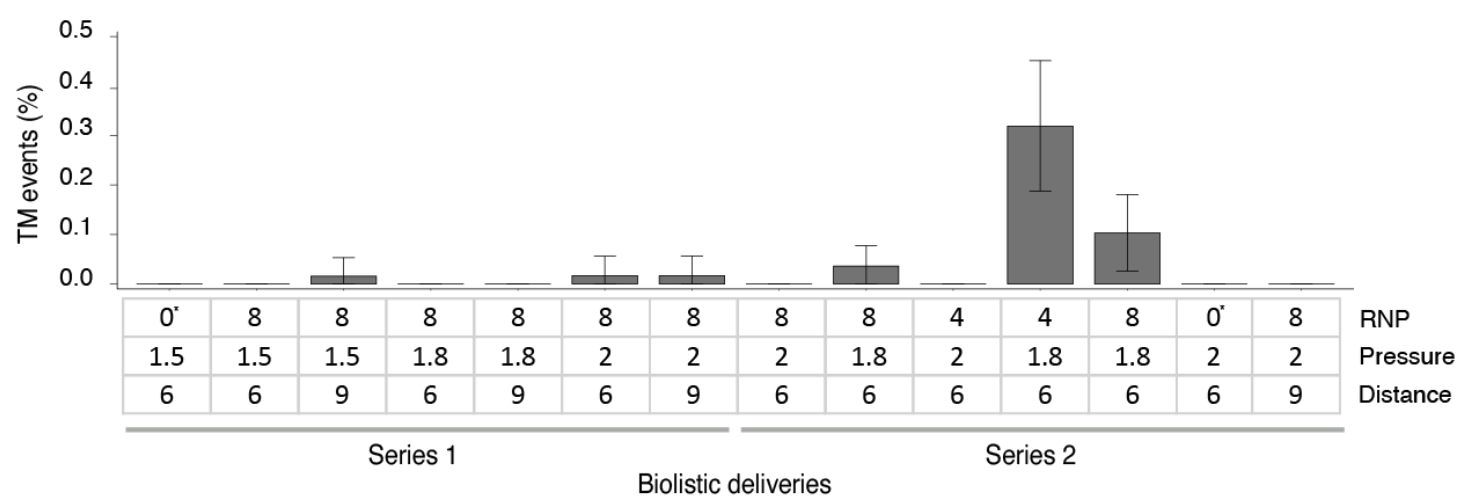

Fig. 3. ddPCR detection of targeted mutagenesis events in gametophytes subjected to biolistic delivery of CRISPR-Cas9 RNPs. (a) Oligonucleotides employed for the drop-off ddPCR assay that was used to detect mutations in the second exon of the FKBP12 gene. The PCR primers (FKBddPCR-F and FKB-ddPCR-R, purple bars) and the reference probe (FKB-ddPCR-HEX, yellow bar) were designed distant from the site targeted by the CRISPR-Cas9 RNP complex whereas the cut site probe (FKB-ddPCR-FAM, green bar) overlapped the site targeted by the crRNA (gFKB12Ex2-23f, grey arrow). The protospacer adjacent motif (PAM) is in bold. See Supplementary Table S1 for details of the primers and crRNA. Fluorescent labels: FAM, 5(6)-carboxyfluorescein; HEX, hexachloro-fluorescein. (b) Frequencies of targeted mutagenesis events detected in 14 independent biolistic delivery experiments. Two series of biolistic experiments (series 1 and series 2) were carried out using gametes produced by two independently derived sets of gametophytes. Within each series, each Petri dish of target gametes was derived from a different gametophyte culture. Controls $\left(^{*}\right)$ were bombarded with Cas9 alone (8 $\left.\mu \mathrm{g}\right)$. Frequencies of targeted mutagenesis events are expressed as ratios of single HEX (i.e. mutant) over double HEX+FAM (i.e. wild type) fluorescent signals in droplets. Error bars correspond to the Poisson corrected fractional abundance calculated by the Quantasoft software. TM, targeted mutagenesis, RNP, ribonucleoprotein. Units for amounts of RNP complex, pressure and distance to the target are $\mu \mathrm{g}$, psi and $\mathrm{cm}$, respectively. 
(a)

\begin{tabular}{|l|c|c|c|c|} 
crRNA & $\begin{array}{c}\text { Total } \\
\text { shots }\end{array}$ & $\begin{array}{c}\text { 2-FAR } \\
\text { individuals }\end{array}$ & $\begin{array}{c}\text { Validated } \\
\text { TMs }\end{array}$ & $\begin{array}{c}\text { Successful } \\
\text { shots }\end{array}$ \\
\hline gAPT1 & 8 & 8 & 3 & 3 \\
\hline gAPT2 & 3 & 5 & 3 & 2 \\
\hline
\end{tabular}

(b)

Untreated

2-FA

Cas9 alone

Cas9-gAPT1
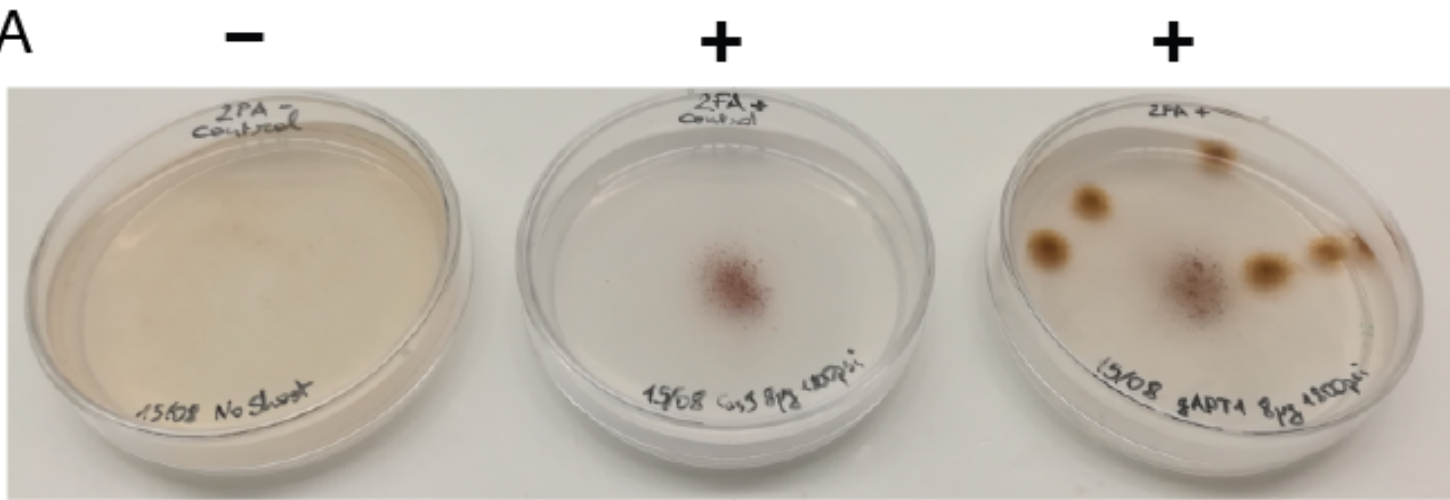

(c)

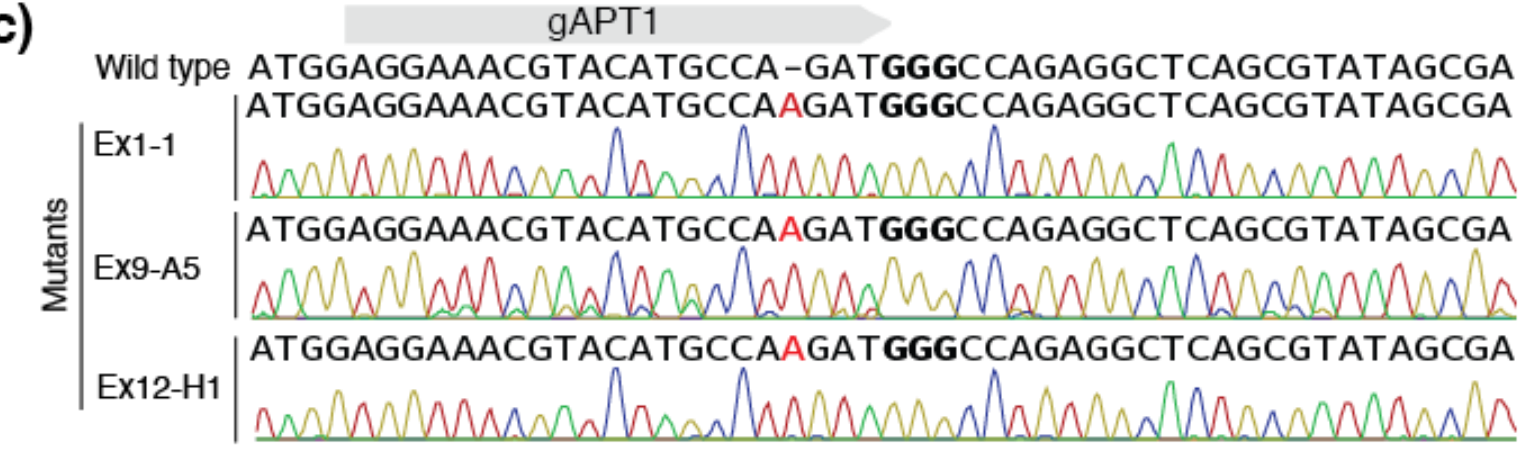

(d) gAPT2

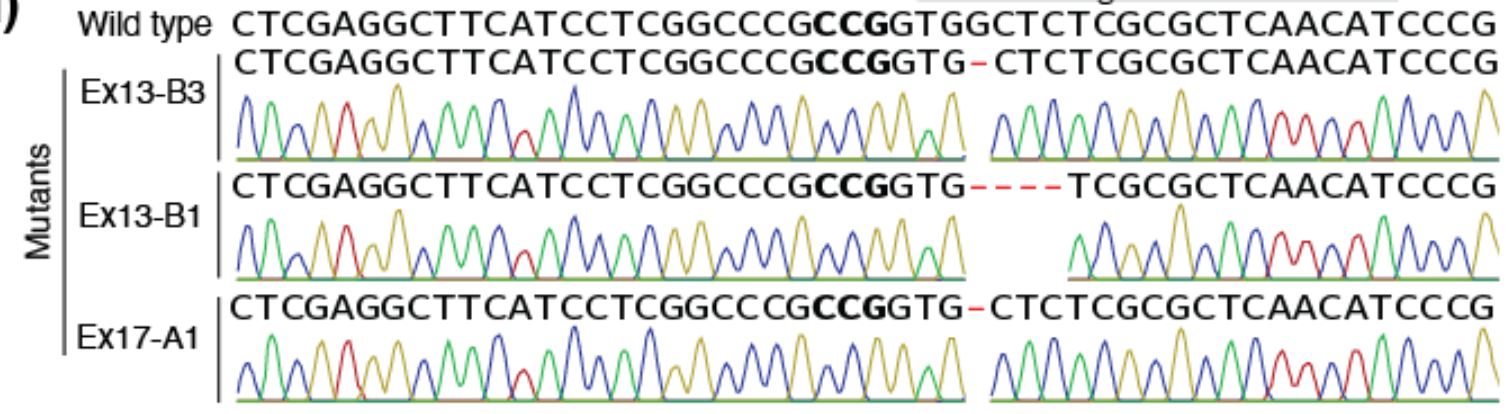


Fig. 4. Isolation of individuals with mutations in the $A P T$ gene following biolistic delivery of CRISPR-Cas9 RNPs. (a) Number of 2-FAR individuals and confirmed targeted mutagenesis (TM) events obtained in 11 experiments using either the gAPT1 or gAPT2 crRNA. Validated TM indicates the number of 2-FAR individuals in which a TM event was detected by Sanger sequencing. "Successful shot" indicates the number of experiments where at least one TM event was detected. (b) Biolistic experiment showing five 2-FAR individuals obtained after biolistic delivery of gAPT1 RNPs (the more diffuse brown mark in the centre of the Petri dish corresponds to the bombarded gold beads). The three Petri dishes correspond to untreated gametes (left) or to gametes exposed to 2-FA following bombardment either with $8 \mu \mathrm{g}$ Cas 9 with no crRNA (middle) or with $8 \mu$ g of gAPT1 RNPs (right). Note that the Petri dishes were photographed three months post-bombardment when the 2-FAR individuals were clearly visible but 2-FAR candidates can be detected using a stereomicroscope as early as three to four weeks post-bombardment. (c,d) Sanger sequence chromatograms for the six 2-FAR individuals obtained using gAPT1 (c) or gAPT2 (d) crRNAs. Protospacer adjacent motifs (PAMs) are in bold. 
(a)

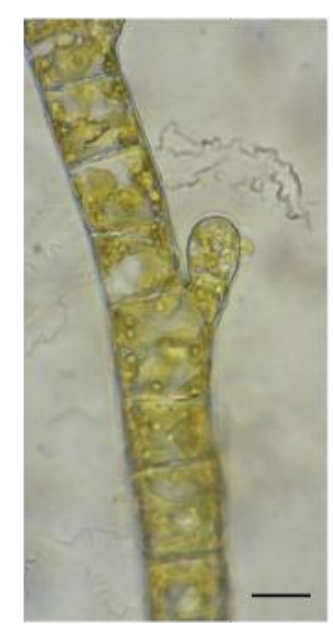

(b) Wild type 2-FA resistant

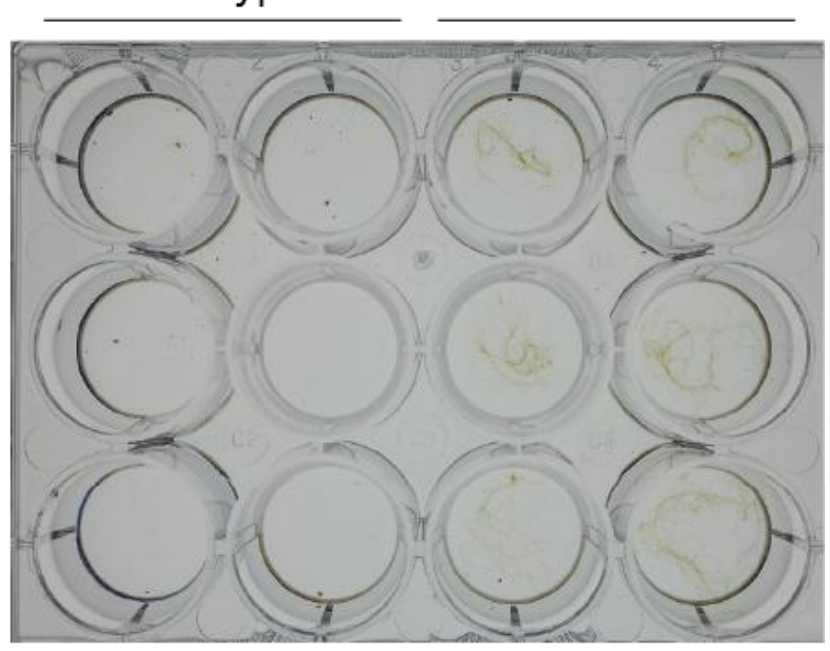

(c)

\begin{tabular}{|c|c|c|}
\hline $\begin{array}{c}\text { Unilocular } \\
\text { sporangium }\end{array}$ & crRNA & $\begin{array}{c}\text { No of 2-FAR } \\
\text { individuals with apt } \\
\text { mutation }\end{array}$ \\
\hline 1 & gAPT1 & 7 \\
\hline 2 & gAPT1 & 4 \\
\hline
\end{tabular}

(d)

gAPT1

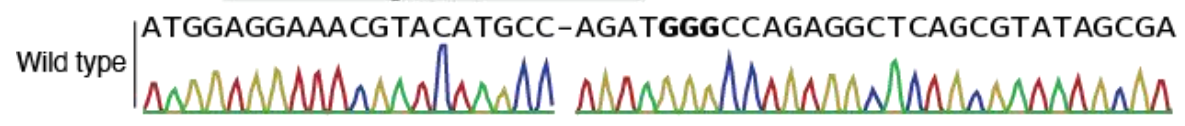

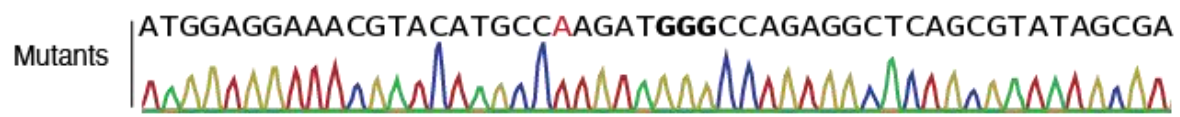

Fig. 5. Isolation of 2-FAR gametophytes after microinjection of unilocular sporangia. (a) A 8-16 nucleate stage unilocular sporangium after microinjection. Scale bar: $20 \mu \mathrm{m}$. (b) Wild type and 2-FAR gametophytes that were cultured in a multiwell plate in half strength PES containing 20 $\mu \mathrm{M} 2$ 2-FA for 9 days at $15^{\circ} \mathrm{C}$ with long day illumination. The 2-FAR gametophytes correspond to six of the seven individuals derived from the first unilocular sporangia microinjected with the gAPT1 CRISPR-Cas9 RNP targeting the APT gene. (c) Summary of the 2-FAR individuals isolated following microinjection of each of the two unilocular sporangia. (d) Location of the single inserted adenine residue (in red) detected at the target site in all 11 of the 2-FAR individuals isolated following microinjection. The region corresponding to the gAPT1 crRNA is indicated by 
a grey arrow and the PAM is shown in bold. A representative chromatogram is shown for the mutant individuals. 
(a)

\begin{tabular}{|c|c|c|c|c|}
\hline crRNAs & $\begin{array}{c}\text { Total shots } \\
\text { or injections }\end{array}$ & $\begin{array}{c}\text { Number of } \\
\text { 2-FAR individuals }\end{array}$ & Percent single TM & Percent double TM \\
\hline gAPT1 + gAPT2 & 1 & 8 & $50 \%$ & $0 \%$ \\
\hline gAPT2 + gAPT3 & 1 & 1 & $0 \%$ & $100 \% *$ \\
\hline gAPT1 + gFKB12 & 9 & 8 & $75 \%$ & $13 \%$ \\
\hline gAPT1 + vBPO-ex6-228f & 5 & 2 & $50 \%$ & $50 \%$ \\
\hline gAPT1 + Mas1-C & 25 & 22 & $31 \% * *$ & $69 \% * *$ \\
\hline
\end{tabular}

(b)

Wild type ATGGAGGAAACGTACATGCCA-GATGGGCCAGAGGCTCAGCGTATAGCGA Ex13-A4 ATGGAGGAAACGTACATGCCA--ATGGGCCAGAGGCTCAGCGTATAGCGA Ex13-A6 ATGGAGGAAACGTACATGCCAAGATGGGCCAGAGGCTCAGCGTATAGCGA Ex23-A2 ATGGAGGAAACGTACATGCCAAGATGGGCCAGAGGCTCAGCGTATAGCGA EX23-A3 ATGGAGGAAACGTACATGCC--GATGGGCCAGAGGCTCAGCGTATAGCGA EX23-A4 ATGGAGGAAACGTACATGCCAAGATGGGCCAGAGGCTCAGCGTATAGCGA Ex23-A1 ATGGAGGAAACGTACATGCCA GATGGGCCAGAGGCTCAGCGTATAGCGA 375 bp insertion

(c)

Wild type CTCGAGGCTTCATCCTCGGCCCGCCGGTGEX13-A5 CTCGAGGCTTCATCCTCGGCCCGCCGGTGTGCATAAAACCAAAACCAAAAAAGCGCCGCAGCTCTCGCGCTCAACATCCCG EX13-A3 CTCGAGGCTTCATCCTCGGCCCGCCGG

322 bp deletion

(d) gAPT3 gAPT2 Wild type CTCGAGGCTTCATCCTCGGCC-CGCCGGTG-GCTCTCGCGCTCAACATCCC |CTCGAGGCTTCATCCTCGGCCACGCCGGTGAGCTCTCGCGCTCAACATCCC Mutant Ex10-A1

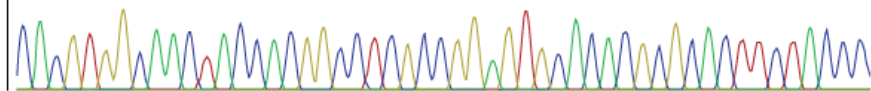

(e)

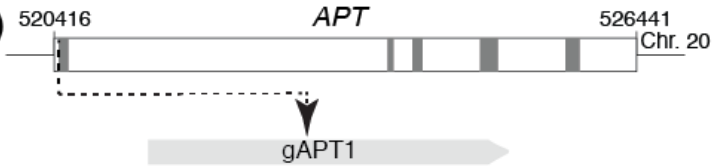

Wild type ATGGAGGAAACGTACATGCCA-GATGGGCCAGAGGCTCAGCGTATAGCGA |ATGGAGGAAACGTACATGCCAAGATGGGCCAGAGGCTCAGCGTATAGCGA Mutant Ex24-B1
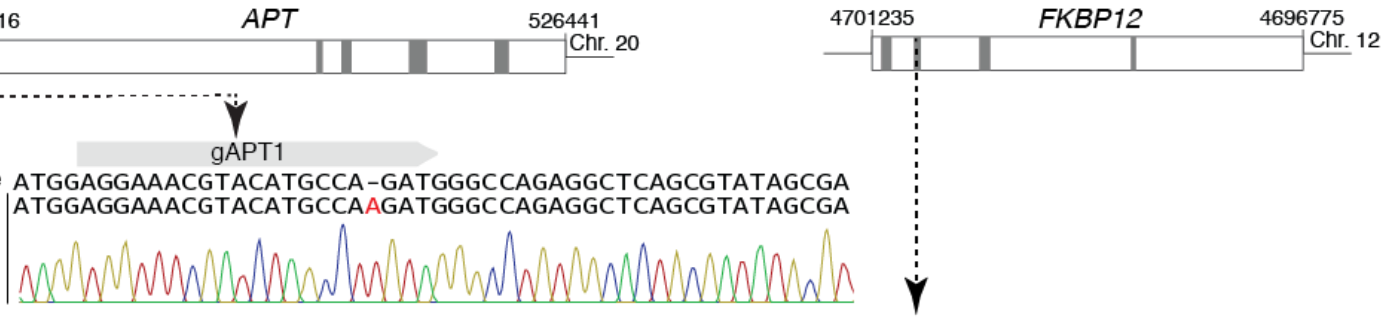

gFKB12-Ex2-23f

Wild type GTGTTCGACAGCTCCATC-CGGAAGGGCAGGCGATTCAACTGCAAGATCGG Mutant |GTGTTCGACAGCTCCATCCCGGAAGGGCAGGCGATTCAACTGCAAGATCGG Mutant

(f)

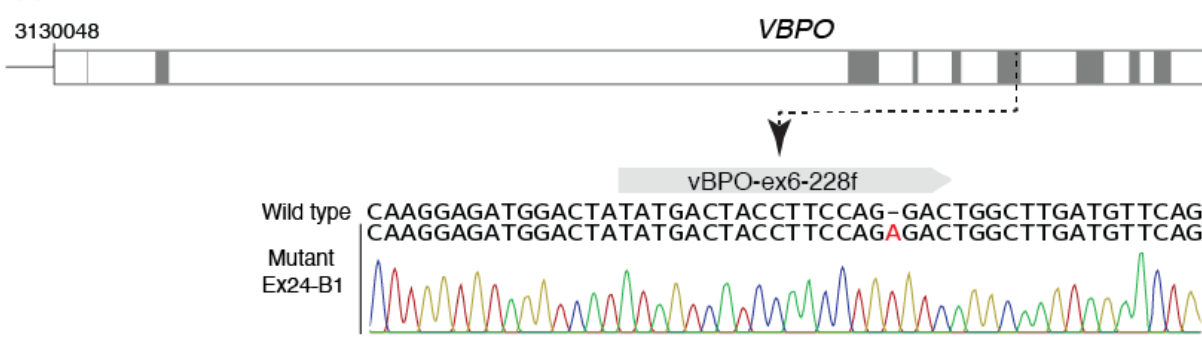

(g)

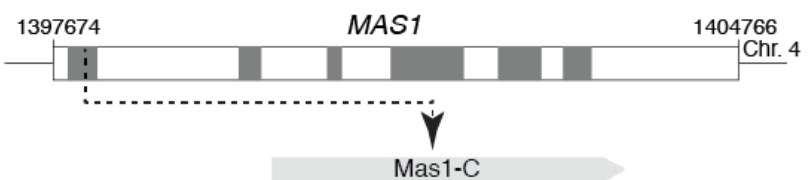

Wild type cCCCTTTGGCCTTGCGCACGTCGACTCCCC-TAAGGGAGATCTTAA Mutant $\mid$ CCCCTTTGGCCTTGCGCACGTCGACTCCCCCTAAGGGAGATCTTAA TM1-1-APT-MA

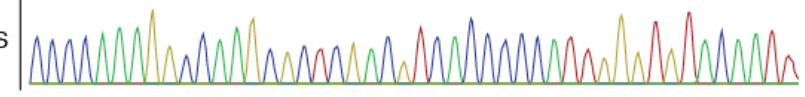


Fig. 6. Simultaneous recovery of mutations in a selectable gene and in a second, target gene. (a) Percentages of confirmed single and double targeted mutagenesis (TM) events observed in 41 experiments that used combinations of two different CRISPR-Cas9 RNPs. *In this case the two mutations were in two different regions of the $A P T$ gene. ${ }^{* *}$ Estimations based on sequencing of 13 of the 22 2-FAR individuals. (b,c) Diversity of single TM events obtained at the gAPT1 (b) and gAPT2 (c) target sites. (d) Detection of a double TM event at the APT locus. (e) Detection of a double TM event resulting in the knock-out of both the Ectocarpus species 7 APT and FKB12 genes after biolistic introduction of a mixture of CRISPR-Cas9 RNPs targeting the two genes. (f) Detection of a mutation in the $V B P O$ gene after simultaneous biolistic introduction of a mixture of two CRISPR-Cas9 RNPs targeting APT and VBPO. (g) Detection of a mutation in the MAS1 gene after simultaneous microinjection of a mixture of two CRISPR-Cas9 RNPs targeting APT and MAS1. Only the mutations in the $V B P O$ and MAS1 genes are shown and only one representative chromatogram is shown for the mas1 mutants. For the gene drawings, open boxes correspond to the transcribed regions of the genes, grey boxes to coding sequence. Transcription is from left to right. Chr. 20, chromosome 20; Chr. 12, chromosome 12; Chr. 4, chromosome 4. 